\title{
Marshall-Olkin Lehmann Lomax Distribution: Theory, Statistical Properties, Copulas and Real Data Modeling
}

\author{
Mohamed Aboraya*
}

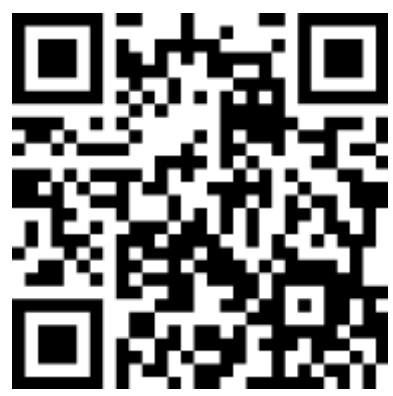

Department of Applied, Mathematical and Actuarial Statistics, Faculty of Commerce, Damietta University, Damietta, Egypt. E-mail: mohamedaboraya17@gmail.com

*Corresponding Author

\begin{abstract}
In this work, a new four-parameter lifetime probability distribution called the Marshall-Olkin Lehmann Lomax distribution is defined and studied. The density function of the new distribution "asymmetric right skewed" and "symmetric" and the corresponding hazard rate can be monotonically increasing, increasing-constant, constant, upside down and monotonically decreasing. The coefficient of skewness can be negative and positive. We derive some new bivariate versions via Farlie Gumbel Morgenstern family, modified Farlie Gumbel Morgenstern family, Clayton Copula and Renyi's entropy.The method of maximum likelihood is used to estimate the unknown parameters. Using "biases" and "mean squared errors", a simulation study is performed for assessing the finite behavior of the maximum likelihood estimators.
\end{abstract}

Key Words: Lomax model; Marshall-Olkin family; Copula; Simulations; Renyi's entropy; Farlie Gumbel Morgenstern family; Estimation.

Mathematical Subject Classification: 62N01; 62N02; 62E10.

\section{Introduction}

The Lomax or Pareto type II distribution (Lomax (1954)), is a heavy-tail probabilistic model used in modeling business, actuarial science, biological sciences, engineering, economics, income and wealth inequality, queueing theory, size of cities and Internet traffic data sets. Harris (1968) and Atkinson and Harrison (1978) employed the Lomax (Lx) distribution in modeling data obtained from income and wealth. Corbellini et al. (2007) used the Lx distribution firm size data modeling. For applications in reliability and life testing experiments see Hassan Al-Ghamdi (2009). The Lx model is known as a special distribution form of Pearson system (type VI) and has also considered as a mixture of standard exponential (Exp) and standard gamma (Gam) distributions. The Lx model belongs to the family of "monotonically decreasing" hazard rate function (HRF) and considered as a limiting model of residual lifetimes at great age (see Balkema and de Hann (1974) and Chahkandi and Ganjali (2009)). The Lx distribution has been suggested as heavy tailed alternative model to the standard Exp, standard Weibull (W) and standard Gam distributions (see Bryson (1074)). For details about relation between the Lx model and the Burr XII and Compound Gamma (CGam) models see Tadikamalla (1980) and Durbey (1970).

A random variable (rv) $Z$ has the Lx distribution with two parameters $a$ and $\zeta$ if it has cumulative distribution function $(\mathrm{CDF})$ (for $z>0$ ) given by

$$
G_{a, \zeta}(z)=1-\left(\frac{1}{\zeta} z+1\right)^{-a},
$$

where $a>0$ and $\zeta>0$ are the shape and scale parameters, respectively. Then the corresponding probability density function (PDF) of (1) is 


$$
g_{a, \zeta}(z)=\frac{a}{\zeta}\left(\frac{1}{\zeta} z+1\right)^{-(a+1)}
$$

Due to Yousof et al. (2018), the CDF of the Marshall-Olkin Lehmann-G family (MOL-G) family is given by

$$
F_{v, \beta, \underline{\xi}}(z)=\left.\frac{1-\bar{G}_{\underline{\xi}}(z)^{\beta}}{1-\bar{v} \bar{G}_{\underline{\xi}}(z)^{\beta}}\right|_{x \in R},
$$

where $\bar{G}_{\underline{\xi}}(z)=1-G_{\underline{\xi}}(z)$ is the base line survival function $(\mathrm{SF}), G_{\underline{\xi}}(z)$ is the base line CDF and $\bar{v}=(1-v)$. The PDF corresponding to $(3)$ is given by

$$
f_{v, \beta, \underline{\xi}}(z)=\left.v \beta \frac{g_{\underline{\xi}}(z) \bar{G}_{\underline{\xi}}(z)^{\beta-1}}{\left[1-\bar{v} \bar{G}_{\underline{\xi}}(z)^{\beta}\right]^{2}}\right|_{x \in R} .
$$

The Marshall-Olkin Lehmann Lomax (MOLLx) CDF is given by

$$
F_{\underline{V}}(z)=\left.\frac{1-\left(\frac{1}{\zeta} z+1\right)^{-a \beta}}{1-\bar{v}\left(\frac{1}{\zeta} z+1\right)^{-a \beta}}\right|_{x \in R},
$$

where $F_{\underline{V}}(z)=1-\left.F_{\underline{V}}(z)\right|_{(\underline{V}=v, \beta, a, \zeta)}$. The main objectives of this work is to derive a more flexible distribution by adding two extra parameter to the standard base line Lomax model and for improving the goodness-of-fit to real-life data.

The basic motivations for the MOLLx model in practice are:

I. to make the kurtosis more flexible as compared to the baseline base line Lomax model.

II. for producing skewness for symmetrical and asymmetrical distributions.

III. for constructing heavy-tailed densities that are not longer-tailed for modeling various real-life data

IV. for providing consistently better fits than other generated Lomax extensions.

The PDF corresponding to (5) is given by

$$
f_{\underline{V}}(z)=v \beta a \zeta^{-1} \frac{\left(\frac{1}{\zeta} z+1\right)^{-a \beta-1}}{\left[1-\bar{v}\left(\frac{1}{\zeta} z+1\right)^{-a \beta}\right]^{2}} .
$$

The HRF for the new model can be derived from $f_{\underline{V}}(z) / F_{\underline{V}}(z)$. For exploring the flexibility of the MOLLx PDF and the corresponding HRF we sketched Figure 1. Figure 1(left) provides some plots of the new PDF for some carefully selected parameters value. Figure 1(right) provides some plots of the new HRF for some selected parameters value. In this article, we derive some new bivariate MOLLx (BvMOLLx) via Farlie Gumbel Morgenstern (FGM) Copula, modified Farlie Gumbel Morgenstern (FGM) Copula, Renyi's entropy and Clayton Copula. The Multivariate MOLLx (MvMOLLx) type is also presented using the Clayton Copula. However, future works could be allocated to study these new models. For more details see Morgenstern (1956), Farlie (1960), Gumbel (1960 \& 1961), Johnson and Kotz (1975 \& 1976), Pougaza and Djafari (2011) and Rodriguez-Lallena and Ubeda-Flores (2004). Many useful univariate Lx extensions can be found in Tahir et al. (2015) (Weibull Lomax distribution), Cordeiro et al. (2018) (the one parameter Lomax system of densities), Altun et al. (2018a) (Odd log-logistic Lomax), Altun et al. (2018a) (ZografosBalakrishnan Lomax distribution), Elbiely and Yousof (2018) (Weibull generalized Lomax, Rayleigh generalized Lomax and Exponential generalized Lomax distributions), Nasir et al. (2018) (new Weibull Lomax distribution), Yousof et al. (2019) (Topp Leone Poisson Lomax distribution), Goual and Yousof (2020) (Lomax inverse Rayleigh), Gad et al. (2019) (Burr type XII Lomax, Lomax Burr type XII and Lomax Lomax distributions), Aboraya, M. (2019) (the Burr X exponentiated Lomax), Aboraya and Butt (2019) (extended Weibull Lomax distribution), Yadav et al. (2020) (Topp Leone Lomax distribution) and Ibrahim and Yousof (2020) (Poisson Burr X generalized Lomax and Poisson Rayleigh generalized Lomax distributions). Based on Figure 1(left) the MOLLx PDF can be "asymmetric right skewed" and "symmetric". Based on Figure 1(right) the MOLLx HRF can be "monotonically increasing" ( $v=$ $100, \beta=3.5, a=3, \zeta=10)$, " increasing-constant" $(v=100, \beta=3.5, a=5, \zeta=1)$ ", "constant" $(v=150, \beta=$ $10, a=0.1, \zeta=0.5)$, "upside down $(v=0.5, \beta=0.25, a=1, \zeta=2)$ " and "monotonically decreasing" ( $v=$ $0.25, \beta=0.25, a=1, \zeta=2$ ). 

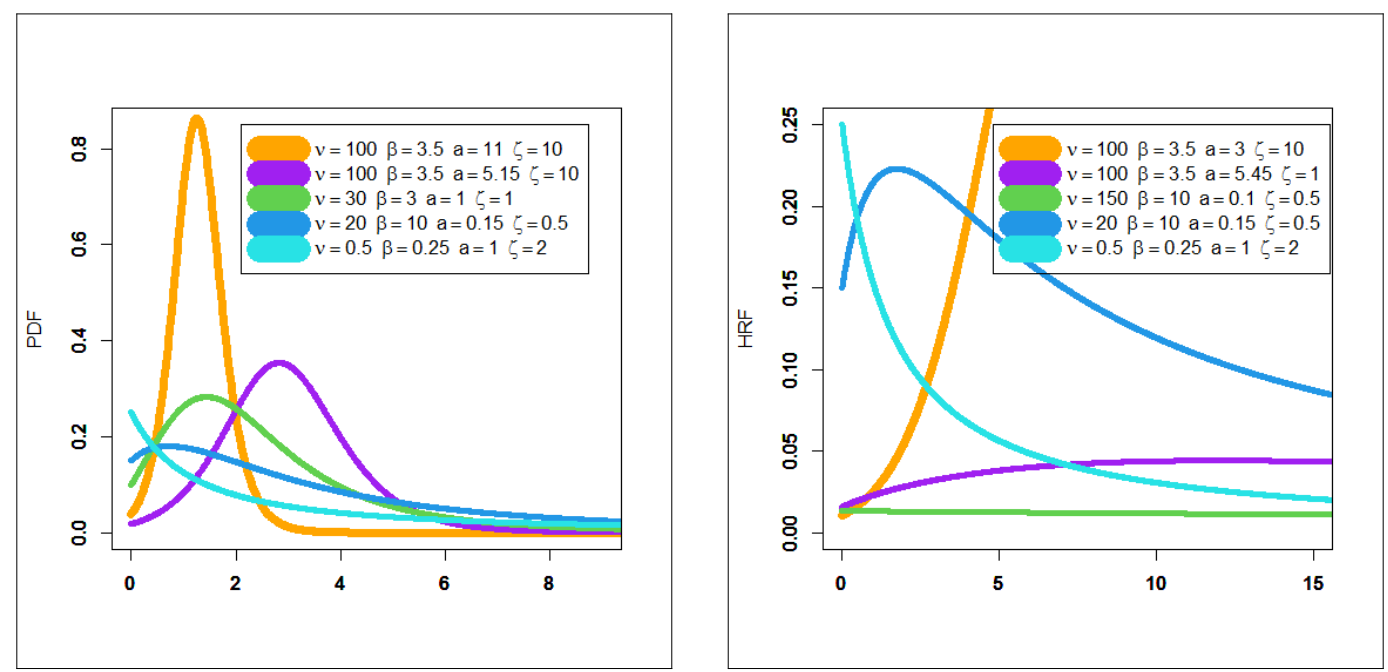

Figure 1: PDF and HRF plots for some selected parameters value.

We are motivated to define and study the MOLLx model for the following reasons:

I. The PDF of the MOLLx model can be "symmetric" and "asymmetric right skewed" with many useful cases. The failure rate of the MOLLx model can be monotonically increasing, increasing-constant, constant, upside down and monotonically decreasing.

II. In statistical modeling, the new MOLLx proved adequate superiority in fitting real-life data sets against many common competitive models including standard base line Lomax, odd log-logistic Lomax, reduced odd loglogistic Lomax, the three-parameter gamma Lomax, the four-parameter Kumaraswamy Lomax, the fiveparameter Macdonald Lomax, reduced MOLLx, reduced Burr-Hatke Lomax, the four-parameter beta Lomax and special generalized mixture Lomax distributions.

III. The MOLLx model showed better fits in modeling the bimodal right skewed and bimodal right skewed data sets. We prove empirically that the MOLLx distribution provides better fits to two real life data sets than other fourteen extended Lomax distributions with two, three and four parameters (see Section 5).

IV. By analyzing the skewness kurtosis coefficients and index of dispersion numerically, it is noted that, skewness coefficient of the MOLLx distribution can be negative and also can be positive. The spread for the kurtosis coefficient of the MOLLx model is ranging from - 7.39 to 4074.332. The index of dispersion for the MOLLx model can be in $(0,1)$ and also $>1$ so it may be used as an "under-dispersed" and "over-dispersed" model (see Table 1).

\section{Copulas}

\subsection{BvMOLLx type via FGM Copula}

Consider the joint CDF (J-CDF) of the FGM family (see Morgenstern (1956), Gumbel (1958) and Gumbel (1960)), then

$$
\left.\mathcal{F}_{\wp \in(-1,1)}(\xi, \varpi)\right|_{\wp \in(-1,1)}=\xi \varpi(1+\wp \bar{\xi} \bar{\varpi}),
$$

where the marginal function $\xi=F_{1}\left(z_{1}\right), \varpi=F_{2}\left(z_{2}\right)$ is a dependence parameter and for every $\xi, \varpi \in(0,1)^{2}$, $\mathcal{F}_{\wp}(\xi, 0)=\mathcal{F}_{\wp}(0, \varpi)=0$ which is "grounded minimum" and $\mathcal{F}_{\wp}(\xi, 1)=\xi$ and $\mathcal{F}_{\wp}(1, \varpi)=\varpi$ which is "grounded maximum". Then for $v=v_{1}=v_{2}$, setting

and

$$
\left.\bar{\xi}=\bar{\xi}_{\underline{V_{1}}}=\left.\frac{1-\varsigma_{z_{1} ; \zeta_{1}}^{-a_{1} \beta_{1}}}{1-\bar{v} S_{z_{1} ; \zeta_{1}}^{-a_{1} \beta_{1}}}\right|_{\varsigma_{z_{1} ; \zeta_{1}}=\left(\frac{1}{\zeta_{1}} z_{1}+1\right.}\right)^{\prime}
$$




$$
\left.\bar{\varpi}=\bar{\varpi}_{\underline{V_{2}}}=\left.\frac{1-\varsigma_{z_{2} ; \zeta_{2}}^{-a_{2} \beta_{2}}}{1-\bar{v} S_{Z_{2} ; \zeta_{2}}^{-a_{2} \beta_{2}}}\right|_{\zeta_{z_{2} ; \zeta_{2}}=\left(\frac{1}{\zeta_{2}} z_{2}+1\right.}\right)^{\prime}
$$

then we have

$$
\begin{aligned}
& \mathcal{F}_{\wp}\left(z_{1}, z_{2}\right)=\mathcal{F}_{\wp}\left(F_{V_{1}}\left(z_{1}\right), F_{V_{2}}\left(z_{2}\right)\right)=\frac{1-\varsigma_{z_{1} ; \zeta_{1}}^{-a_{1} \beta_{1}}}{1-\bar{v} S_{z_{1} ; \zeta_{1}}^{-a_{1} \beta_{1}}} \frac{1-\varsigma_{z_{2} ; \zeta_{2}}^{-a_{2} \beta_{2}}}{1-\bar{v} S_{z_{2} ; \zeta_{2}}^{-a_{2} \beta_{2}}} \\
& \times\left(1+\wp\left\{\begin{array}{c}
\left(1-\frac{1-\varsigma_{z_{1} ; \zeta_{1}}^{-a_{1} \beta_{1}}}{1-\bar{v} S_{z_{1} ; \beta_{1}}^{-\beta_{1}}}\right) \\
\times\left(1-\frac{1-S_{z_{2} ; \zeta_{2}}^{-a_{2} \beta_{2}}}{1-\bar{v} S_{z_{2} ; \zeta_{2}}^{-a_{2} \beta_{2}}}\right)
\end{array}\right\}\right) .
\end{aligned}
$$

\subsection{BvMOLLx type via modified FGM Copula}

Consider the following modified version of the bivariate FGM copula defined as (see Rodriguez-Lallena and UbedaFlores (2004))

$$
\left.\mathcal{F}_{\wp}(\xi, \varpi)\right|_{\wp \in[-1,1]}=\xi \varpi\left[1+\wp \varphi_{(\xi)} \psi_{(\xi)}\right]=\xi \varpi+\wp K_{(\xi)} Q_{(\varpi)},
$$

where $K_{(\xi)}=\xi \varphi_{(\xi)}$, and $Q_{(\varpi)}=\varpi \psi_{(\xi)}$. Where $\varphi_{(\xi)}$ and $\psi_{(\xi)}$ are two absolutely continuous functions on $(0,1)$ with the following conditions:

1-The boundary condition:

$$
\varphi(\xi=0)=\varphi(\xi=1)=\psi(\varpi=0)=\psi(\varpi=1)=0 .
$$

2-Let

$$
\begin{gathered}
\varsigma_{1}=\inf \left\{\left.\frac{\partial}{\partial \xi} K_{(\xi)}\right|_{A_{1}(\xi)}\right\}<0, \varsigma_{2}=\sup \left\{\left.\frac{\partial}{\partial \xi} K_{(\xi)}\right|_{A_{1}(\xi)}\right\}<0, \\
\pi_{1}=\inf \left\{\left.\frac{\partial}{\partial \varpi} Q_{(\varpi)}\right|_{A_{2}(\varpi)}\right\}>0, \pi_{2}=\sup \left\{\left.\frac{\partial}{\partial \varpi} Q_{(\varpi)}\right|_{A_{2}(\varpi)}\right\}>0,
\end{gathered}
$$

Then,

where

$$
\min \left(\varsigma_{1} \varsigma_{2}, \pi_{1} \pi_{2}\right) \geq 1,
$$

$$
\begin{gathered}
\frac{\partial}{\partial \xi} K_{(\xi)}=\varphi_{(\xi)}+\xi \frac{\partial}{\partial \xi} \varphi_{(\xi)}, \\
A_{1}(\xi)=\left\{\xi:\left.\quad \xi \in(0,1)\right|_{\frac{\partial}{\partial \xi} K_{(\xi)}} \text { exists }\right\},
\end{gathered}
$$

and

$$
A_{2}(\varpi)=\left\{\varpi:\left.\varpi \in(0,1)\right|_{\frac{\partial}{\partial \varpi}} Q_{(\varpi)} \text { exists }\right\} .
$$

\section{Type I modified FGM:}

Here, we consider the following functional form for both $\varphi_{(\xi)}$ and $\psi(\varpi)$ as

where

$$
\mathcal{F}_{\wp}(\xi, \varpi)=\left(\frac{1-\varsigma_{\xi ; \zeta_{1}}^{-a_{1} \beta_{1}}}{1-\bar{v} \varsigma_{\xi ; \zeta_{1}}^{-a_{1} \beta_{1}}} \times \frac{1-\varsigma_{\zeta ; \zeta_{2}}^{-a_{2} \beta_{2}}}{1-\bar{v} \varsigma_{\zeta ; \zeta_{2}}^{-a_{2} \beta_{2}}}\right)+\wp K_{(\xi)} Q_{(\varpi)},
$$

$$
K_{(\xi)}=\xi-\xi \frac{1-\varsigma_{\xi ; \zeta_{1}}^{-a_{1} \beta_{1}}}{1-\bar{v}_{\zeta}^{-a_{1} \beta_{1}}}
$$


and

$$
Q_{(\varpi)}=\varpi-\varpi \frac{1-\varsigma_{\varpi ; \zeta_{2}}^{-a_{2} \beta_{2}}}{1-\bar{v} \varsigma_{\varpi ; \zeta_{2}}^{-a_{2} \beta_{2}}}
$$

\section{Type II modified FGM:}

The CDF of the BvMOLLx-FGM (Type II) model can be derived from

$$
\mathcal{F}_{\S}(\xi, \varpi)=\xi F^{-1}(\varpi)+\varpi F^{-1}(\xi)-F^{-1}(\xi) F^{-1}(\varpi) .
$$

\section{Type III modified FGM:}

Consider the following functional form for both $\varphi_{(\xi)}$ and $\psi(\varpi)$ which satisfy all the conditions stated earlier where

and

$$
\left.\varphi_{(\xi)}\right|_{\left.\wp_{1}>0\right)}=\xi^{\wp_{1}}(1-\xi)^{1-\wp_{1}}
$$

$$
\left.\psi(\varpi)\right|_{\left(\wp_{2}>0\right)}=\varpi^{\wp_{2}}(1-\varpi)^{1-\wp_{2}} .
$$

The corresponding bivariate copula (henceforth, BvMOLLx-FGM (Type III) copula) can be derived from

$$
\mathcal{F}_{\wp_{0}, \wp_{1}, \wp_{2}}(\xi, \varpi)=\xi \varpi\left[1+\wp_{0} \xi^{\wp_{1}} \varpi^{\wp_{2}}(1-\xi)^{1-\wp_{1}}(1-\varpi)^{1-\wp_{2}}\right] .
$$

\section{Type IV modified FGM:}

Consider the following functional form for both $K_{(\xi)}$ and $Q_{(\varpi)}$ which satisfy all the conditions stated earlier where

and

$$
\varphi(\xi)=\left.\xi K_{(\xi)}\right|_{K_{(\xi)}=[\log (1+\bar{\xi})]},
$$

$$
\psi(\varpi)=\left.\varpi Q_{(\varpi)}\right|_{Q_{(\varpi)}=[\log (1+\bar{\varpi})]} .
$$

In this case, one can also derive a closed form expression for the associated CDF of the BvMOLLx-FGM (Type IV) as

$$
\mathcal{F}_{\wp}(\xi, \varpi)=\xi \varpi(1+\wp \varphi(\xi) \psi(\varpi)) .
$$

\subsection{BvMOLLx type via Renyi's entropy}

Consider theorem of Pougaza and Djafari (2011) where

$$
\mathcal{F}(\xi, \varpi)=z_{2} \xi+z_{1} \varpi-z_{1} z_{2}
$$

where $\xi$ and $\varpi$ are two absolutely continuous functions on $(0,1)$. Then, the associated BvMOLLx will be

$$
\mathcal{F}\left(z_{1}, z_{2}\right)=\mathcal{F}\left(F_{\underline{V_{1}}}\left(z_{1}\right), F_{\underline{V_{2}}}\left(z_{2}\right)\right)=-z_{1} z_{2}+z_{2} \frac{1-\varsigma_{z_{1} ; \zeta_{1}}^{-a_{1} \beta_{1}}}{1-\bar{v} S_{z_{1} ; \zeta_{1}}^{-a_{1} \beta_{1}}}+z_{1} \frac{1-\varsigma_{z_{2} ; \zeta_{2}}^{-a_{2} \beta_{2}}}{1-\bar{v} \zeta_{z_{2} ;}^{-a_{2} \beta_{2}}} .
$$

\subsection{BvMOLLx type via Clayton Copula}

The Clayton Copula can be considered as

$$
\mathcal{F}_{\wp}\left(\zeta_{1}, \zeta_{2}\right)=\left.\left(\varpi_{1}^{-\wp}+\varpi_{2}^{-\wp}-1\right)^{-\frac{1}{\wp}}\right|_{\wp \in[0, \infty]}
$$

Let us assume that $Y \sim \operatorname{MOLLx}\left(V_{1}\right)$ and $Z \sim \operatorname{MOLLx}\left(\underline{V}_{2}\right)$. Then, setting

and

$$
\varpi_{1}=\varpi\left(y \mid \underline{V_{1}}\right)=\frac{1-\varsigma_{z_{1} ; \zeta_{1}}^{-a_{1} \beta_{1}}}{1-\bar{v} S_{y ; \zeta_{1}}^{-a_{1} \beta_{1}}}
$$

Then, the BvMOLLx type distribution can be derived as

$$
\varpi_{2}=\varpi\left(z \mid \underline{V_{2}}\right)=\frac{1-\varsigma_{z_{2} ; \zeta_{2}}^{-a_{2} \beta_{2}}}{1-\bar{v} S_{z ; \zeta_{2}}^{-a_{2} \beta_{2}}}
$$




$$
F_{\wp}(y, z)=\mathcal{F}_{\wp}\left(F_{\underline{V_{1}}}(z), F_{\underline{V_{2}}}(z)\right)=\left[\left(\frac{1-\varsigma_{y ; \zeta_{1}}^{-a_{1} \beta_{1}}}{1-\bar{v} S_{y ; \zeta_{1}}^{-a_{1} \beta_{1}}}\right)^{-\wp}+\left(\frac{1-\varsigma_{z ; \zeta_{2}}^{-a_{2} \beta_{2}}}{1-\bar{v} \varsigma_{z ; \zeta_{2}}^{-a_{2} \beta_{2}}}\right)^{-\wp}-1\right]^{-\frac{1}{\wp}} .
$$

\subsection{MvMOLLx extention via Clayton Copula}

A straightforward $n$-dimensional extension from the above will be

Then, the MvMOLLx extention can expressed as

$$
\mathcal{F}\left(\varpi_{i}\right)=\left[\sum_{i=1}^{n} \varpi_{i}^{-\wp}+1-n\right]^{-\frac{1}{\wp}}
$$

$$
\mathcal{F}(\underline{Z})=\left[\sum_{i=1}^{n}\left(\frac{1-S_{Z ; \zeta_{1}}^{-a_{1} \beta_{1}}}{1-\bar{v} S_{z ; \zeta_{1}}^{-a_{1} \beta_{1}}}\right)^{-\wp}+1-n\right]^{-\frac{1}{\wp}}
$$

where $\underline{Z}=z_{1}, z_{2}, \cdots, z_{n}$. Recently, many authors used the above mentioned copulas to generate some new bivariate models such as see Elgohari and Yousof (2020a,b), Al-babtain et al. (2020), Elgohari et al. (2021), Mansour et al. (2020b,c,f) and Ali et al. (2021a,b).

\section{Mathematical properties}

\subsection{The quantile function $(\mathrm{QF})$}

For simulation of the MOLLx model, we obtain the QF of $Z$ by inverting (5), say $z_{u}=F^{-1}(u)$, as

$$
z_{u}=\varpi\left(\frac{1-u}{1-\bar{v} u}\right)^{-\frac{1}{a \beta}}-1,
$$

Equation (7) is used for simulating the new model.

\subsection{Linear combinations}

Let

and

$$
A_{\beta, a, \zeta}(z)=1-\left[\left(\frac{1}{\zeta} z+1\right)^{-a}\right]^{\beta}
$$

$$
B_{v, \beta, a, \zeta}(z)=1-\bar{v}-\left[\left(\frac{1}{\zeta} z+1\right)^{-a}\right]^{\beta} .
$$

Then, by expanding the quantity $A_{\beta, a, \zeta}(z)$ we get

which can be repressed as

$$
A_{\beta, a, \zeta}(z)=1+\sum_{\mathfrak{i}=0}^{\infty}\left(\begin{array}{c}
\beta \\
\mathfrak{i}
\end{array}\right)(-1)^{\mathfrak{i}+1}\left[1-\left(\frac{1}{\zeta} z+1\right)^{-a}\right]^{\mathfrak{i}},
$$

$$
A_{\beta, a, \zeta}(z)=\sum_{i=0}^{\infty} c_{i}\left[1-\left(\frac{1}{\zeta} z+1\right)^{-a}\right]^{i}
$$

where $c_{0}=2$ and

$$
c_{\mathfrak{i}}=\left.(-1)^{i+1}\left(\begin{array}{c}
\beta \\
\mathfrak{i}
\end{array}\right)\right|_{i \geq 1} .
$$

Similarly, we expand the quantity $B_{v, \beta, a, \zeta}(z)$ we get

which can be re-written as

$$
B_{v, \beta, a, \zeta}(z)=1-\bar{v}-\sum_{\mathfrak{i}=0}^{\infty}\left(\begin{array}{c}
\beta \\
\mathfrak{i}
\end{array}\right)(-1)^{\mathfrak{i}}\left[1-\left(\frac{1}{\zeta} z+1\right)^{-a}\right]^{\mathfrak{i}},
$$

where $d_{0}=v$ and

$$
B_{v, \beta, a, \zeta}(z)=\sum_{\mathfrak{i}=0}^{\infty} d_{\mathfrak{i}}\left[1-\left(\frac{1}{\zeta} z+1\right)^{-a}\right]^{\mathfrak{i}},
$$




$$
d_{\mathfrak{i}}=(1-v)\left(\begin{array}{c}
\beta \\
\mathfrak{i}
\end{array}\right)(-1)^{i+1} .
$$

Using (8) and (9), the CDF of the MOLLx model can be expressed as

$$
F(x)=\sum_{\mathrm{i}=0}^{\infty} \nabla_{\mathrm{i}} H_{\mathrm{i}, a, \zeta}(z)
$$

where $H_{\mathrm{i}, a, \zeta}(z)=G_{a, \zeta}^{\mathfrak{i}}(z)$ is the CDF of the exponentiated-Lx (expLx) distribution with power parameter $\mathfrak{i}$ and

$$
\boldsymbol{\nabla}_{\mathfrak{i}}=\frac{1}{\beta_{0}}\left(c_{\mathfrak{i}}-\frac{1}{d_{0}} \sum_{i=1}^{\mathrm{i}} d_{i} \boldsymbol{\nabla}_{\mathrm{i}-i}\right) \mathrm{I}_{\left(\boldsymbol{\nabla}_{0}=\frac{c_{0}}{d_{0}} \text { and } \mathrm{i} \geq 1\right)} .
$$

The PDF of the MOLLx model can also be expressed as a mixture of expLx densities. By differentiating (10), we obtain

$$
f(x)=\sum_{i=0}^{\infty} \nabla_{i} h_{i+1, a, \zeta}(z),
$$

where $h_{\mathfrak{i}+1, a, \zeta}(z)$ is the exp-G pdf with power parameter $\mathfrak{i}+1$. Equation (11) reveals that the MOLLx density is a linear combination of expLx densities.

\subsection{Moments and incomplete moments}

The $r^{\text {th }}$ ordinary moment of $Z$ is given by

Then, we obtain

$$
\mu_{r}^{\prime}=E\left(Z^{r}\right)=\int_{-\infty}^{\infty} z^{r} f(z) d z
$$

$$
\mu_{r}^{\prime}=\left.\sum_{\mathrm{i}=0}^{\infty} \sum_{\mathrm{i}=0}^{r} \boldsymbol{\nabla}_{\mathrm{i}, \mathrm{j}}^{(r, \mathrm{i}+1)} B\left(\mathfrak{i}+1,1+\frac{\mathrm{i}-r}{a}\right)\right|_{(a>r)},
$$

where

and

$$
\nabla_{\mathrm{i}, \mathrm{i}}^{(r, \mathrm{i}+1)}=\nabla_{\mathfrak{i}}(\mathfrak{i}+1) \zeta^{r}(-1)^{\mathrm{i}}\left(\begin{array}{l}
r \\
\mathfrak{j}
\end{array}\right)
$$

Setting $r=1,2,3$ and 4 in (12), we have

$$
B\left(1+\nabla_{1}, 1+\nabla_{2}\right)=\int_{0}^{1} z^{\nabla_{1}}(1-z)^{\nabla_{2}} d z
$$

$$
\begin{aligned}
& E(Z)=\left.\sum_{\mathrm{i}=0}^{\infty} \sum_{\mathrm{j}=0}^{1} \nabla_{\mathrm{i}, \mathrm{i}}^{(1, \mathrm{i}+1)} B\left(\mathfrak{i}+1,1+\frac{\mathrm{i}-1}{a}\right)\right|_{(a>1)}, \\
& E\left(Z^{2}\right)=\left.\sum_{\mathrm{i}=0}^{\infty} \sum_{\mathrm{i}=0}^{2} \nabla_{\mathrm{i}, \mathrm{i}}^{(2, \mathrm{i}+1)} B\left(\mathfrak{i}+1,1+\frac{\mathfrak{i}-2}{a}\right)\right|_{(a>2)}, \\
& E\left(Z^{3}\right)=\left.\sum_{\mathrm{i}=0}^{\infty} \sum_{\mathrm{i}=0}^{3} \nabla_{\mathrm{i}, \mathrm{j}}^{(3, \mathrm{i}+1)} B\left(\mathfrak{i}+1,1+\frac{\mathfrak{i}-3}{a}\right)\right|_{(a>3)} \text {, }
\end{aligned}
$$

and

$$
E\left(Z^{4}\right)=\left.\sum_{\mathrm{i}=0}^{\infty} \sum_{\mathrm{i}=0}^{4} \nabla_{\mathrm{i}, \mathrm{i}}^{(4, i+1)} B\left(\mathfrak{i}+1,1+\frac{\mathrm{i}-4}{a}\right)\right|_{(a>4)},
$$

where $E(Z)=\mu_{1}^{\prime}$ is the mean of $Z$. The $r^{t h}$ incomplete moment, say $I_{r, Z}(t)$, of $Z$ can be expressed, from (11), as

then

$$
I_{r, Z}(t)=\int_{-\infty}^{t} z^{r} f(z) d z=\sum_{\mathfrak{i}=0}^{\infty} \nabla_{\mathfrak{i}} \int_{-\infty}^{t} z^{r} g_{(i+1), a, \zeta}(z) d z
$$


where

$$
I_{r, Z}(t)=\left.\sum_{\mathfrak{i}=0}^{\infty} \sum_{\mathrm{i}=0}^{r} \nabla_{\mathfrak{i}, \mathrm{j}}^{(r, \mathfrak{i}+1)} B_{t}\left(\mathfrak{i}+1,1+\frac{\mathfrak{i}-r}{a}\right)\right|_{(a>r)},
$$

$$
B .\left(1+\nabla_{1}, 1+\nabla_{2}\right)=\int_{0}^{\cdot} z^{\nabla_{1}}(1-z)^{\nabla_{2}} d z .
$$

The first incomplete moment given by (11) with $r=1$ as

$$
I_{1, Z}(t)=\left.\sum_{\mathfrak{i}=0}^{\infty} \sum_{\mathrm{j}=0}^{1} \nabla_{\mathrm{i}, \mathrm{j}}^{(\mathrm{i}+1,1)} B_{t}\left(\mathfrak{i}+1,1+\frac{\mathfrak{i}-1}{a}\right)\right|_{(a>1)} .
$$

The index of dispersion or the variance $\left(\mu_{2}\right)$ to mean ratio can derived as $\varpi_{3}=\mu_{2} / \mu_{1}^{\prime}$. It is a measure used to quantify whether a set of observed occurrences are clustered or dispersed compared to a standard statistical model. By analyzing the $\mu_{1}^{\prime}, \mu_{2}$, skewness $\left(\varpi_{1}\right)$, kurtosis $\left(\varpi_{2}\right)$ and index of dispersion $\left(\varpi_{3}\right)$ numerically in Table 1 , it is noted that, $\varpi_{1}$ of the MOLLx distribution can be negative and also can be positive. The spread for the $\varpi_{2}$ of the MOLLx model is ranging from -7.39 to $4074.332 . \varpi_{3}$ for the MOLLx model can be in $(0,1)$ and also $>1$ so it

\begin{tabular}{|c|c|c|c|c|c|c|c|c|}
\hline $\mathrm{v}$ & $\beta$ & $\mathrm{a}$ & $\zeta$ & $\mu_{1}^{\prime}$ & $\mu_{2}$ & $\varpi_{1}$ & $\varpi_{2}$ & $\varpi_{3}$ \\
\hline 0.001 & 2.5 & 5 & 1.5 & 0.000864 & $5.647 \times 10^{-5}$ & 47.31053 & 4074.332 & 0.0653639 \\
\hline 0.1 & & & & 0.032184 & 0.00409487 & 5.917603 & 63.94869 & 0.1272322 \\
\hline 1 & & & & 0.130435 & 0.02025385 & 2.604833 & 15.08099 & 0.1552795 \\
\hline 5 & & & & 0.272988 & 0.04310323 & 1.622992 & 8.27171 & 0.1578945 \\
\hline 20 & & & & 0.446573 & 0.06741704 & 1.169473 & 6.374351 & 0.1509653 \\
\hline 50 & & & & 0.583525 & 0.08451235 & 0.991622 & 5.882405 & 0.1448307 \\
\hline 100 & & & & 0.697485 & 0.09793459 & 0.901599 & 5.701340 & 0.1404111 \\
\hline 500 & & & & 0.994056 & 0.13193170 & 0.7883849 & 5.562328 & 0.1327207 \\
\hline 1000 & & & & 1.135383 & 0.14846850 & 0.7651884 & 5.551947 & 0.1307651 \\
\hline \multirow[t]{6}{*}{10} & 1 & 10 & 3.5 & 1.0733910 & 0.53976820 & 1.5413920 & 8.445287 & 0.5028627 \\
\hline & 5 & & & 0.1854106 & 0.01244474 & 0.9335028 & 4.673276 & 0.0671199 \\
\hline & 20 & & & 0.0451593 & 0.00070616 & 0.8439966 & 4.367185 & 0.0156371 \\
\hline & 50 & & & 0.0179706 & 0.00011084 & 0.8975597 & 5.019658 & 0.0061683 \\
\hline & 100 & & & 0.0089699 & $2.7537 \times 10^{-5}$ & 2.4910310 & -7.394433 & 0.0030699 \\
\hline & 500 & & & 0.0017915 & $5.5370 \times 10^{-8}$ & -1.287901 & 1.417819 & 0.0030907 \\
\hline \multirow[t]{7}{*}{5} & 5 & 1 & 0.5 & 0.27956670 & 0.06823911 & 3.343108 & 43.06675 & 0.24408880 \\
\hline & & 5 & & 0.04273023 & 0.00094183 & 1.323417 & 6.166525 & 0.02204137 \\
\hline & & 10 & & 0.02072564 & 0.00020992 & 1.263248 & 5.123288 & 0.01012858 \\
\hline & & 15 & & 0.01367977 & $8.98601 \times 10^{-5}$ & 0.942479 & 6.534942 & 0.00656883 \\
\hline & & 20 & & 0.01020898 & $4.96127 \times 10^{-5}$ & 0.774829 & 5.618974 & 0.00485971 \\
\hline & & 30 & & 0.00677238 & $1.92783 \times 10^{-5}$ & 3.658889 & -3.595795 & 0.00284660 \\
\hline & & 40 & & 0.00506676 & $8.22651 \times 10^{-6}$ & 6.387813 & 3.625264 & 0.00162363 \\
\hline \multirow[t]{6}{*}{2} & 2 & 20 & 0.5 & 0.017857 & 0.000240 & 1.695597 & 7.575607 & 0.013449 \\
\hline & & & 1 & 0.035714 & 0.000961 & 1.690192 & 7.598406 & 0.026898 \\
\hline & & & 20 & 0.714288 & 0.384260 & 1.690192 & 7.598212 & 0.537962 \\
\hline & & & 50 & 1.785719 & 2.401624 & 1.690192 & 7.598212 & 1.344906 \\
\hline & & & 100 & 3.571438 & 9.606494 & 1.690192 & 7.598212 & 2.689812 \\
\hline & & & 500 & 17.85719 & 240.1624 & 1.690192 & 7.598212 & 13.44906 \\
\hline
\end{tabular}
may be used as an "under-dispersed" and "over-dispersed" model.

Table 1: $\mu_{1}{ }^{\prime}, \mu_{2}, \varpi_{1}, \varpi_{2}$ and $\varpi_{3}$ of the MOLLx model. 


\subsection{Some generating functions (GF)}

The moment generating function (MGF) can be derived using (8) as

$$
M_{Z}(t)=\sum_{\mathfrak{i}=0}^{\infty} \nabla_{\mathfrak{i}} M_{(\mathrm{i}+1), a, \zeta}(t),
$$

where $M_{(i+1), a, \zeta}(t)$ is the MGF of the expLx model, then

where

$$
M_{Z}(t)=\left.\sum_{\mathrm{i}, r=0}^{\infty} \sum_{\mathrm{i}=0}^{r} \nabla_{\mathrm{i}, \mathrm{j}, r}^{(r, i+1)} B\left(\mathfrak{i}+1,1+\frac{\mathfrak{i}-r}{a}\right)\right|_{(a>r)},
$$

$$
\boldsymbol{\nabla}_{\mathrm{i}, \mathrm{j}, r}^{(r, \mathrm{i}+1)}=t^{r} \boldsymbol{\nabla}_{\mathrm{i}, \mathrm{j}}^{(r, \mathrm{i}+1)} / r \text { ! }
$$

The first $r$ derivatives of $M_{Z}(t)$, with respect to $t$ at $t=0$, yield the first $r$ moments about the origin, i.e.,

$$
\mu_{r}^{\prime}=E\left(z^{r}\right)=\left.\frac{d^{r}}{d t^{r}} M_{z}(t)\right|_{(t=0 \text { and } r=1,2,3, \ldots)},
$$

The cumulant GF (CGF) is the logarithm of the MGF. Thus, $r$ th cumulant, say $\mathfrak{i}_{r}$, can be obtained from

$$
K_{r}=\left.\frac{d^{r}}{d t^{r}} \log \left[\sum_{\mathrm{i}, r=0}^{\infty} \sum_{\mathrm{i}=0}^{r} \nabla_{\mathrm{i}, \mathrm{j}, r}^{(r, i+1)} B\left(\mathfrak{i}+1,1+\frac{\mathrm{i}-r}{a}\right)\right]\right|_{(t=0 \text {, and } r=1,2,3, \ldots)} .
$$

The first cumulant is the mean ( $\dot{i}_{1}=\mu_{1}^{\prime}$ ), the second cumulant is the variance, and the $r^{\text {th }}$ cumulant is the same as the third central moment $K_{3}=\mu_{3}$. But fourth and higher order cumulants are not equal to central moments, that being said

and

$$
K_{1}=\mu_{1}^{\prime}, K=\mu_{2}^{\prime}-\mu_{1}^{\prime 2}=\mu_{2}
$$

$$
K_{3}=\mu_{3}^{\prime}-3 \mu_{2}^{\prime} \mu_{1}^{\prime}+2 \mu_{1}^{\prime 3}=\mu_{3} \text {. }
$$

In some cases, theoretical treatments of problems in terms of cumulants are simpler than those using moments. In particular, when two or more RVs are statistically independent, the $r^{\text {th }}$ order cumulant of their sum is equal to the sum of their $r^{t h}$ order cumulants. Moreover, the cumulants can be also obtained from

$$
\left.K_{r}\right|_{r \geq 1}=\mu_{r}^{\prime}-\sum_{m=0}^{r-1} \mu_{r-m}^{\prime}\left(\begin{array}{c}
r-1 \\
m-1
\end{array}\right) \dot{i}_{m}
$$

\subsection{Reversed residual life function}

The $n^{\text {th }}$ moment of the reversed residual life, say

uniquely determines $F(z)$. We obtain

$$
V_{n, t, Z}(t)=E\left[\left.(t-Z)^{n}\right|_{z \leq t, t>0} \text { and } n=1,2, \ldots\right]
$$

$$
V_{n, t, Z}(t)=\frac{1}{F(t)} \int_{0}^{t}(t-z)^{n} d F(z)
$$

Then, the $n^{\text {th }}$ moment of the reversed residual life of $Z$ becomes

where

$$
V_{n, t, Z}(t)=\left.\frac{1}{F(t)} \sum_{\mathrm{i}=0}^{\infty} \sum_{\mathrm{i}=0}^{r} \nabla_{\mathrm{i}, \mathrm{i}}^{(\mathrm{i}+1, n)}(t, Z) B_{t}\left(\mathfrak{i}+1,1+\frac{\mathrm{i}-r}{a}\right)\right|_{(a>r)},
$$

$$
\nabla_{\mathrm{i}, \mathrm{j}}^{(\mathrm{i}+1, n)}(t, Z)=\nabla_{\mathfrak{i}}(\mathrm{i}+1) \zeta^{r}(-1)^{\mathrm{i}}\left(\begin{array}{l}
r \\
\mathfrak{j}
\end{array}\right) \sum_{d=0}^{n}(-1)^{d}\left(\begin{array}{l}
n \\
d
\end{array}\right) t^{n-d} .
$$

\section{The maximum likelihood estimation (MLE) method}

Let $z_{1}, z_{2}, \ldots, z_{n}$ be a random sample from size $n$ from the MOLLx distribution with parameters $v, \beta, a$ and $\zeta$. Let $\underline{V}$ ? be the $4 \times 1$ parameter vector. For determining the MLE of $\underline{V}$, we have the log-likelihood function

$$
\ell=\ell(\underline{V})=n \log \left(v \beta a \zeta^{-1}\right)-(a \beta+1) \sum_{i=1}^{n} \log \left(\frac{1}{\zeta} z+1\right)-2 \sum_{i=1}^{n} \log \left[1-\bar{v}\left(\frac{1}{\zeta} z+1\right)^{-a \beta}\right]
$$


The components of the score vector,

$$
U(\underline{V})=\frac{\partial \ell(\underline{V})}{\partial \underline{V}}=\left(\frac{\partial \ell(\underline{V})}{\partial v}, \frac{\partial \ell(\underline{V})}{\partial \beta}, \frac{\partial \ell(\underline{V})}{\partial a}, \frac{\partial \ell(\underline{V})}{\partial \zeta}\right)^{T},
$$

are available if needed. Setting $U(v)=U(\beta)=U(a)=U(\zeta)=0$ and solving them simultaneously yields the MLEs. To solve these equations, it is usually more convenient to use nonlinear optimization methods such as the quasi-Newton algorithm to numerically maximize $\ell(\underline{V})$. For interval estimation of the parameters, we obtain the $4 \times 4$ observed information matrix

$$
J(\underline{V})=\left.\left\{\partial^{2} \ell(\underline{V}) / \partial m \partial w\right\}\right|_{(m, w=v, \beta, a, \zeta)} .
$$

The maximum likelihood estimators and the Bayesian estimators are equivalent asymptotically, that can be expressed as

$$
\begin{gathered}
n^{0.5}\left(\underline{\hat{V}}_{(\text {Bayesian })}-\underline{\hat{V}}_{(\mathrm{MLE})}\right) \stackrel{\text { a.s. }}{\rightarrow} \text { Zero. } \\
\Rightarrow n^{0.5}\left(\underline{\hat{v}}_{(\text {Bayesian })}-\underline{\hat{v}}_{(\mathrm{MLE})}\right) \stackrel{\text { a.s. }}{\rightarrow} \text { Zero, } \Rightarrow n^{0.5}\left(\underline{\hat{\beta}}_{(\text {Bayesian })}-\underline{\hat{\beta}}_{(\mathrm{MLE})}\right) \stackrel{\text { a.s. }}{\rightarrow} \text { Zero }, \\
\Rightarrow n^{0.5}\left(\underline{\hat{a}}_{(\text {Bayesian })}-\underline{\hat{a}}_{(\mathrm{MLE})}\right) \stackrel{\text { a.s. }}{\rightarrow} \text { Zero, } \Rightarrow n^{0.5}\left(\underline{\hat{\zeta}}_{\text {(Bayesian })}-\underline{\hat{\zeta}}_{(\mathrm{MLE})}\right) \stackrel{\text { a.s. }}{\rightarrow} \text { Zero. } .
\end{gathered}
$$

A direct consequence of the above theorem is that all asymptotic properties of the maximum likelihood estimators also hold for the Bayesian estimators (see Ibragimov (1962) and Chao (1970) for more details). Also, since the determination of the MLE is independent of the loss function and the prior measure, the asymptotic properties of Bayesian estimators hold for all priors and loss functions in a certain class. A separate article could be allocated for demonstrating this theorem.

\section{Graphical assessment}

Graphically and using the biases and mean squared errors (MSEs), we can perform the simulation experiments to assess the finite sample behavior of the MLEs. The assessment was based on $N=1000$ replication for all $\left.n\right|_{(n=50,100, \ldots, 500)}$. The following algorithm is considered:

I. Generate $N=1000$ samples of size $\left.n\right|_{(n=50,100, \ldots, 500)}$ from the MOLLx distribution using (7),

II. Compute the MLEs for the $N=1000$ samples,

III. Compute the SEs of the MLEs for the 1000 samples,

IV. Compute the biases and mean squared errors given for $\underline{V}=v, \beta, a, \zeta$. We repeated these steps for $\left.n\right|_{(n=50,100, \ldots, 500)}$ with $v=\beta=a=\zeta=1$, so computing biases $\left(\operatorname{Bias}_{\underline{V}}(n)\right)$ and MSEs for $\underline{V}=v, \beta, a, \zeta$ and $\left.n\right|_{(n=50,100, \ldots, 500)}$.

Figures 2, 3, 4 and 5 gives the biases (left panels) and MSEs (right panels) for $v, \beta, a$ and $\zeta$ respectively. The left panels from show how the biases vary with respect to the sample size $n$. The right panels show how the four MSEs vary with respect to the sample size $n$. From Figures 2, 3, 4 and 5 (left panels), the biases are generally negative and tends to zero as the sample size $n \rightarrow \infty$. From Figures 2, 3, 4 and 5 (right panels), the MSEs decrease to zero as the sample size $n \rightarrow \infty$. 


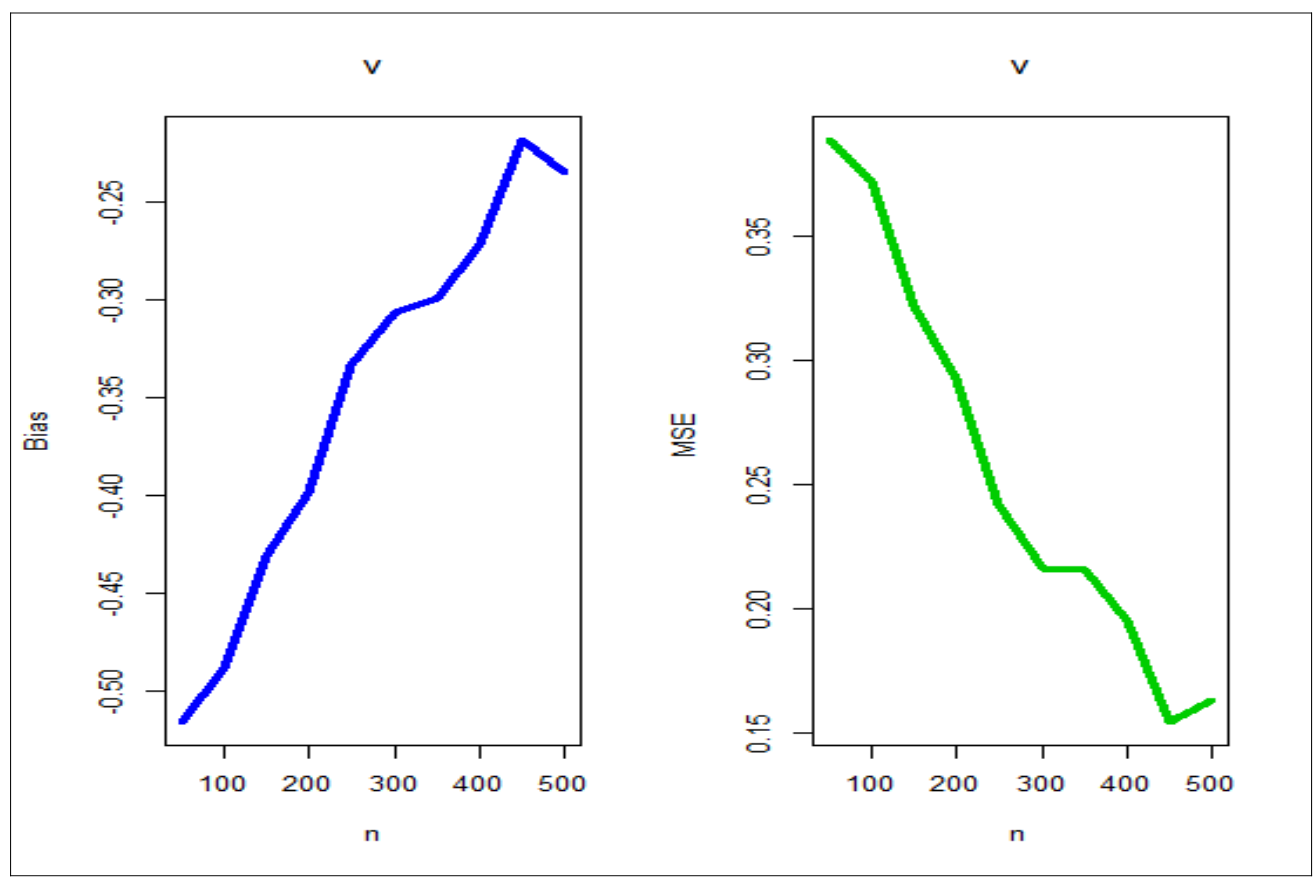

Figure 2: biases and MSEs for the parameter $v$.

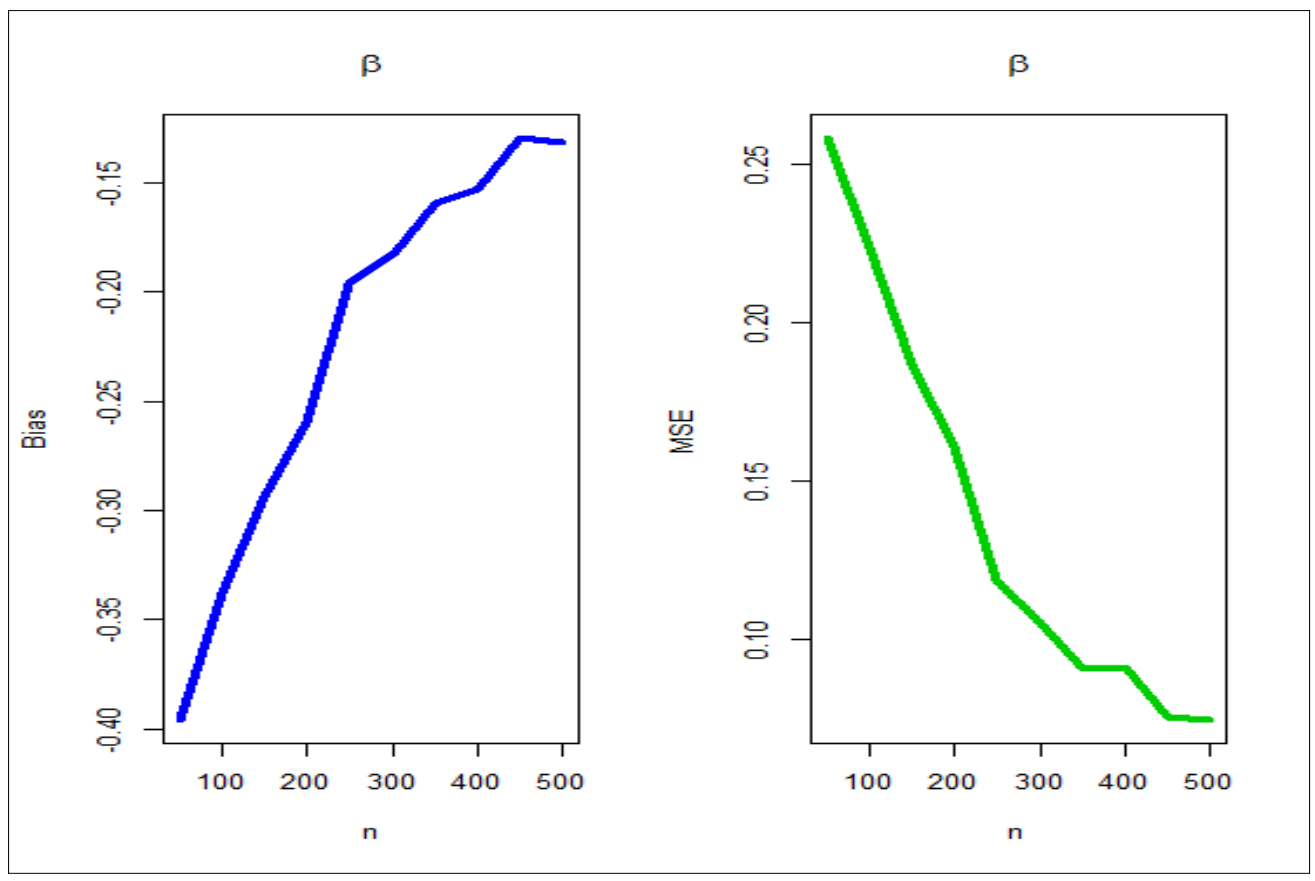

Figure 3: biases and MSEs for the parameter $\beta$. 


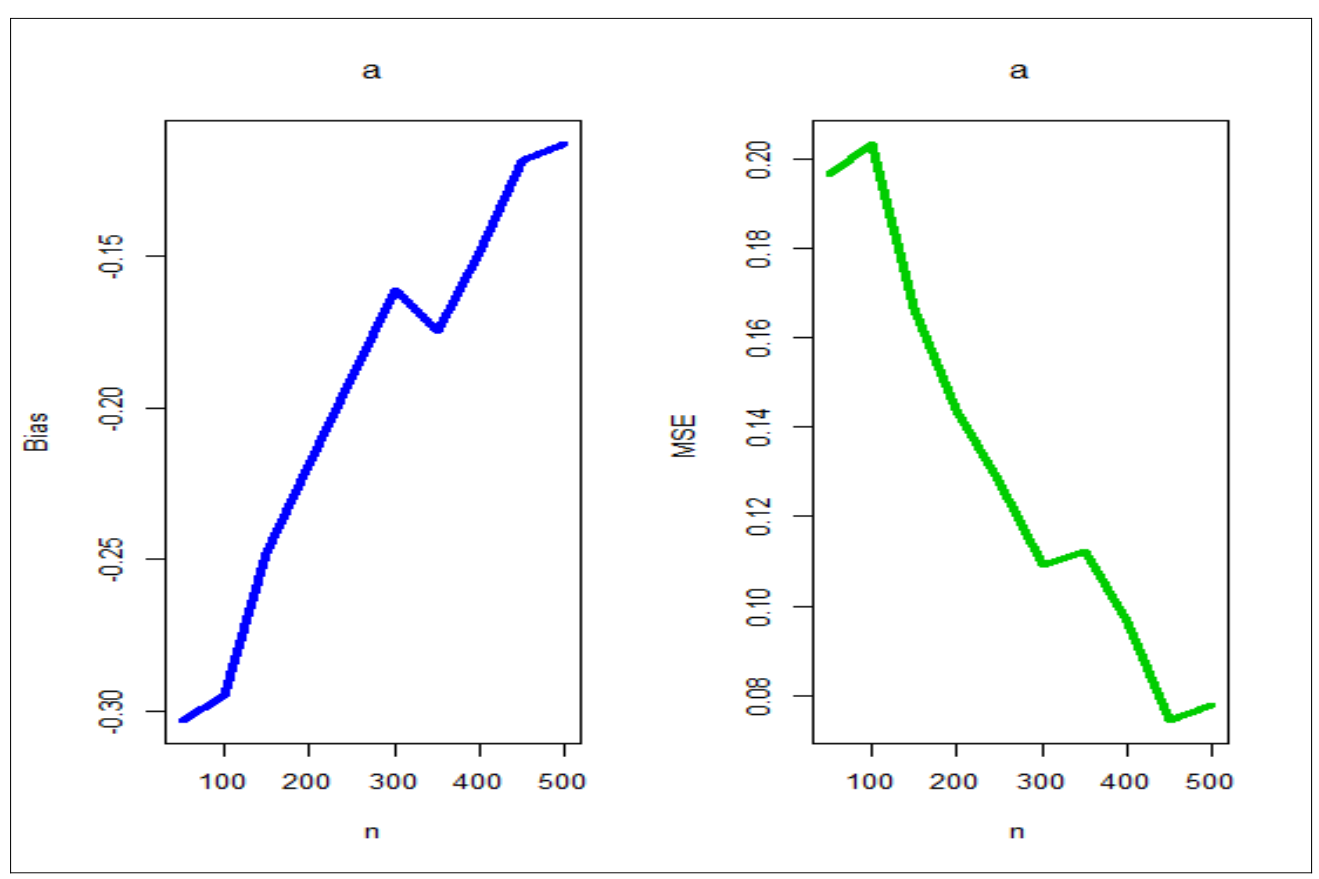

Figure 4: biases and MSEs for the parameter $a$.

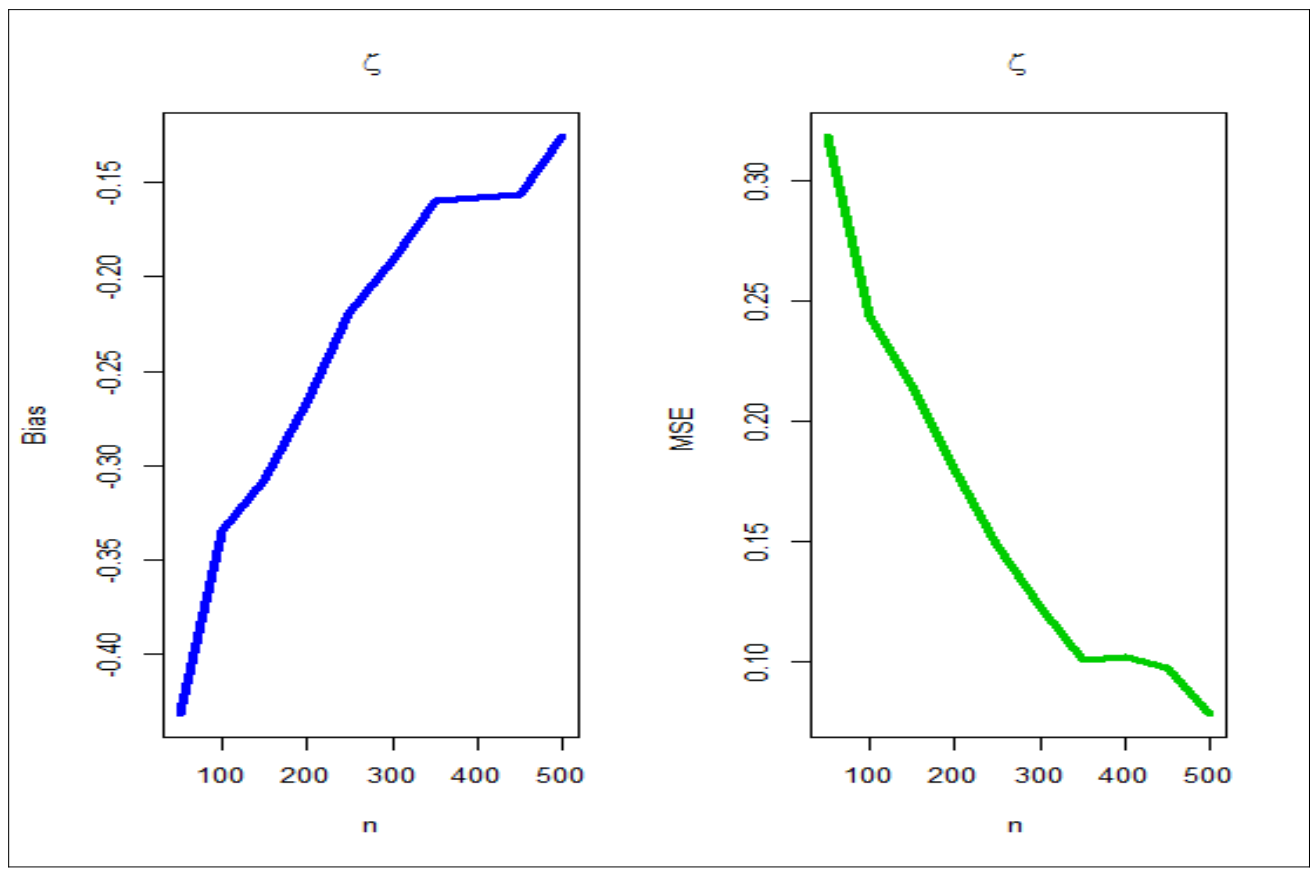

Figure 5: biases and MSEs for the parameter $\zeta$.

\section{Applications}

In this section, we provide two real life applications to two real data sets to illustrate the importance and flexibility of the MOLLx model. We compare the fit of the MOLLx with some well-known competitive models (see Table 2). First 
data set: Failure times of 84 Aircraft Windshield: The first real data set (data set I) represents the data on failure times of 84 aircraft windshield given in Murthy et al. (2004). The data are: $0.0400,1.866,2.3850,3.443,0.3010,1.876$, $2.4810,3.467,0.309,1.8990,2.610,3.4780,0.557,1.9110,2.625,3.5780,0.943,1.9120,2.632,3.5950,1.0700$, $1.914,2.6460,3.699,1.1240,1.981,2.661,3.7790,1.248,2.0100,2.688,3.9240,1.2810,2.038,2.820,3,4.035,1.281$, $2.0850,2.890,4.121,1.3030,2.089,2.902,4.167,1.4320,2.097,2.934,4.2400,1.480,2.135,2.962,4.2550,1.505$, 2.154, 2.9640, 4.278, 1.506, 2.190, 3.000, 4.3050, 1.568, 2.1940, 3.103, 4.376, 1.615, 2.2230, 3.114, 4.449, 1.6190, 2.224, 3.1170, 4.485, 1.652, 2.2290, 3.166, 4.570, 1.652, 2.3000, 3.344, 4.602, 1.7570, 2.324, 3.3760, 4.663 .

Second data set: Service times of 63 Aircraft Windshield: The second real data set (data set II) represents the data on service times of 63 aircraft windshield given in Murthy et al. (2004). The data are: 0.046, 1.436, 2.592, 0.140, 1.492, $2.600,0.150,1.580,2.670,0.248,1.7190,2.717,0.2800,1.794,2.819,0.3130,1.915,2.820,0.389,1.9200,2.878$, $0.487,1.9630,2.950,0.622,1.978,3.0030,0.9000,2.053,3.1020,0.952,2.065,3.3040,0.9960,2.117,3.483,1.0030$, 2.137, 3.500, 1.0100, 2.141, 3.6220, 1.085, 2.163, 3.6650, 1.092, 2.183, 3.695, 1.1520, 2.2400, 4.015, 1.183, 2.3410, $4.628,1.2440,2.435,4.806,1.249,2.4640,4.881,1.262,2.5430,5.140$. Many other useful real life data sets can be found in Aryal et al. (2017), Yousof et al. (2018), Elbiely and Yousof (2018), Ibrahim (2019), Ibrahim (2020a and b), Ibrahim and Yousof (2020), Yadav et al. (2020), Mansour et al. (2020e), Goual et al. (2020).

For exploring the extreme values, the box plot is plotted (see Figure 6). Based on Figure 6, we note that no extreme values were found in the two real life data sets. For checking the normality, the Quantile-Quantile (Q-Q) plot is sketched (see Figure 7). Based on Figures 7, we note that the normality is nearly exists. For exploring the HRF for real data, the total time test (TTT) plot is provided (see Figure 8). Based on Figure 8, we note that the HRF is "monotonically increasing" for the two real life data sets. For exploring the initial shape of real data nonparametrically, kernel density estimation (KDE) is provided (see Figure 9). Figure 9 show nonparametric KDE for exploring the data. Figures 10 and 11 give the estimated Kaplan-Meier survival (EKMS) plot, Probability-Probability (P-P) plot, estimated PDF (EPDF), estimated CDF (ECDF) and estimated HRF (EHRF) for data set I and II respectively.

We estimate the unknown parameters of each model by maximum likelihood using "L-BFGS-B" method and the goodness-of-fit statistics Akaike information criterion (AIC), Bayesian IC (BIC), Consistent AIC (CAIC), HannanQuinn IC (HQIC), Anderson-Darling $\left(A^{*}\right)$ and Cramér-von Mises $\left(W^{*}\right)$ are used to compare the five models. In general, the smaller the values of these statistics, the better the fit to the data. The required computations are obtained by using the "maxLik" and "goftest" sub-routines in R-software. For failure times data: the analysis results of are listed in Tables 3 and 4. Table 3 gives the MLEs and standard errors (SEs) for failure times data. Table 4 gives the $-\hat{\ell}$ and goodness-of-fits statistics for failure times data. For service times data: the analysis results of are listed in Tables 5 and 6. Table 5 gives the MLEs and SEs for service times data. Table 6 give the $-\hat{\ell}$ and goodness-of-fits statistics for the service times data. Based on Tables 4 and 6, we note that the MOLLx model gives the lowest values for the AIC, CAIC, BIC, HQIC, $A^{*}$ and $W^{*}$ among all fitted models. Hence, it could be chosen as the best model under these criteria. 
Table 2: Competitive models.

\begin{tabular}{ccc}
\hline $\mathbf{N}$ & Model & Abbreviation \\
\hline $\mathbf{1}$ & Lomax & Lx \\
$\mathbf{2}$ & Exponentiated Lx & expLx \\
$\mathbf{3}$ & Kumaraswamy Lx & KumLx \\
$\mathbf{4}$ & Macdonald Lx & McLx \\
$\mathbf{5}$ & Beta Lx & BLx \\
$\mathbf{6}$ & Gamma Lx & GamLx \\
$\mathbf{7}$ & Transmuted Topp-Leone Lx & TTLLx \\
$\mathbf{8}$ & Reduced TTLLx & RTTLLx \\
$\mathbf{9}$ & Odd log-logistic Lx & OLLLx \\
$\mathbf{1 0}$ & Reduced OLLLx & ROLLLx \\
$\mathbf{1 1}$ & Reduced Burr-Hatke Lx & RBHLx \\
$\mathbf{1 2}$ & Special generalized mixture Lomax & SGMLx \\
$\mathbf{1 3}$ & Reduced MOLLx & RMOLLx \\
$\mathbf{1 4}$ & Proportional reversed hazard rate Lx & PRHRLx \\
\hline
\end{tabular}

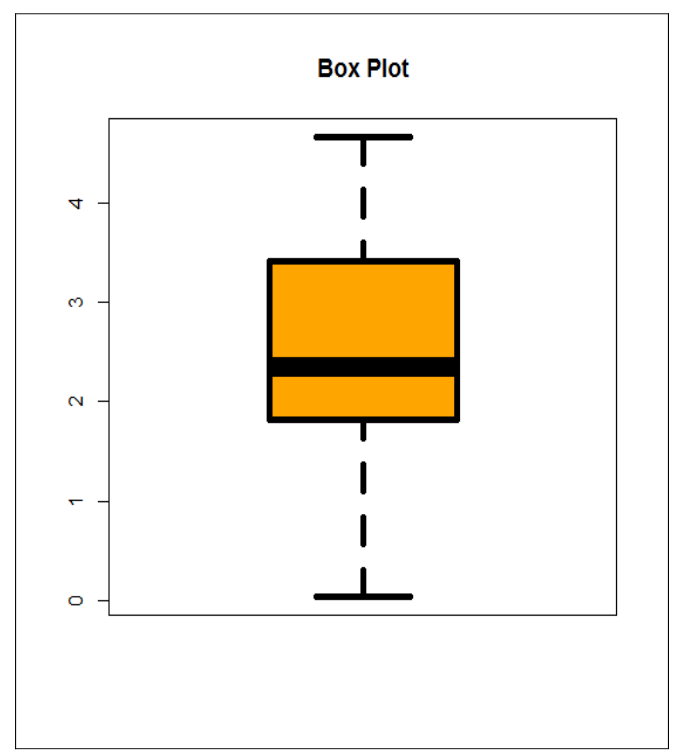

Failure times data

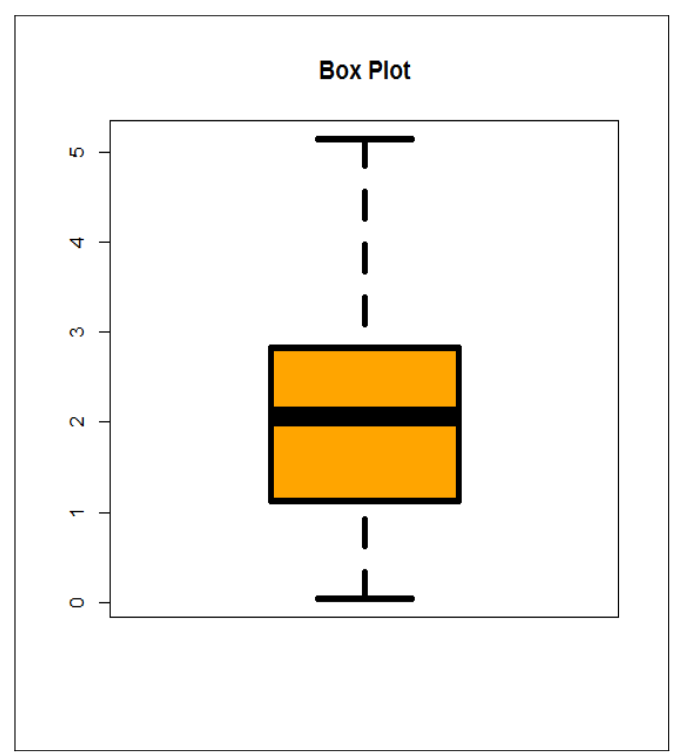

Service times data

Figure 6: Box plots. 


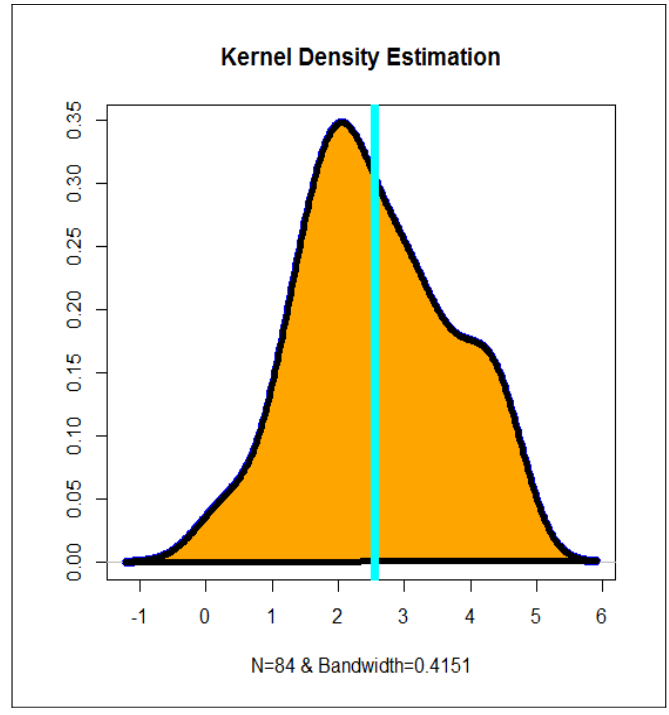

Failure times data

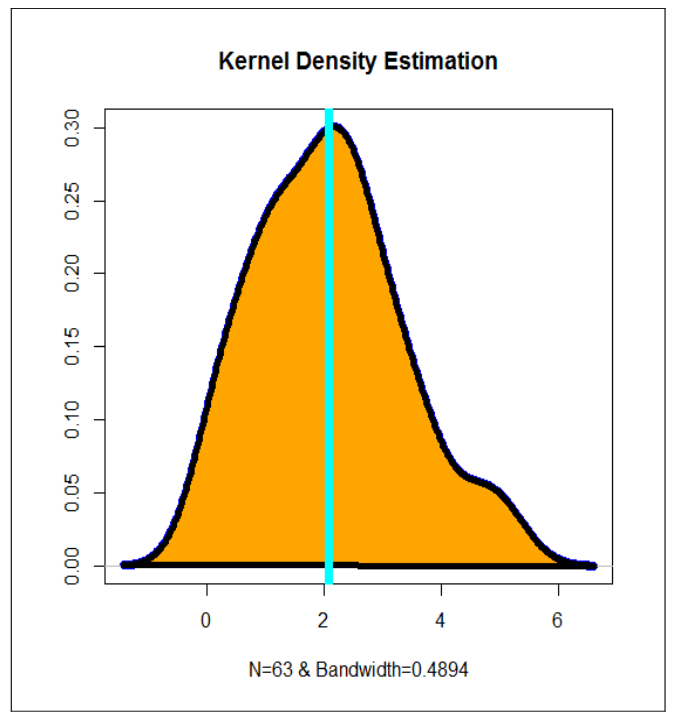

Service times data

Figure 9: Nonparametric KDE.

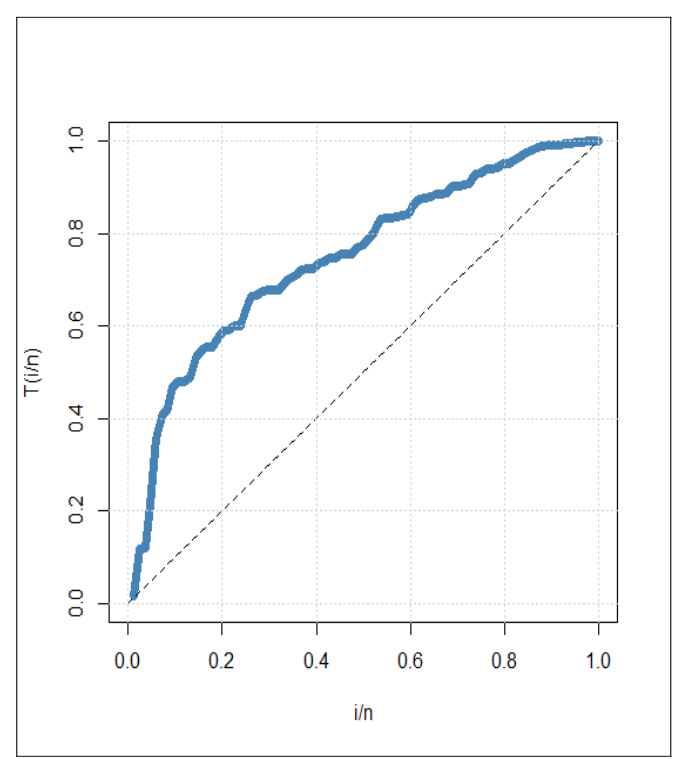

Failure times data

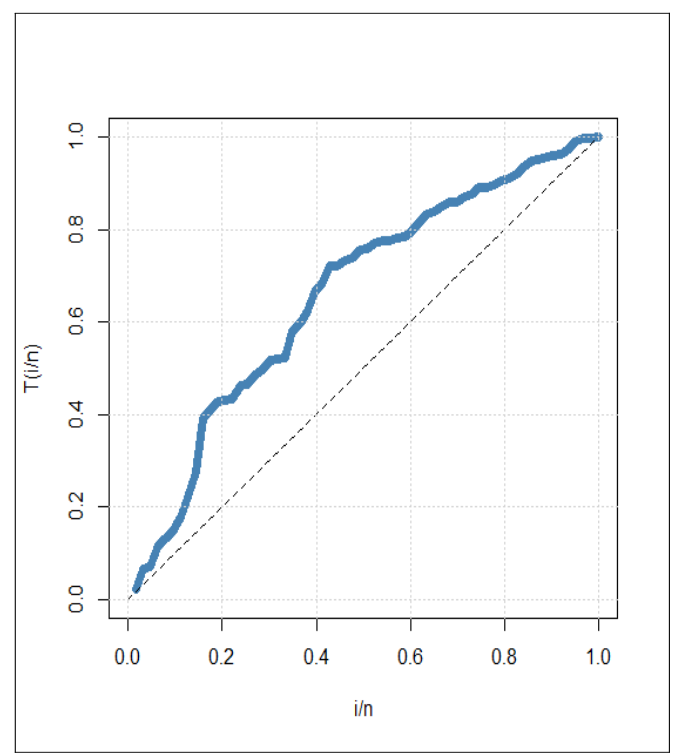

Service times data

Figure 8: TTT plots. 
Table 3: MLEs and SEs for data set $\mathbf{I}$.

\begin{tabular}{|c|c|c|c|c|c|}
\hline \multirow{3}{*}{$\frac{\text { Model }}{\operatorname{MOLLx}(\mathrm{v}, \beta, \mathrm{a}, \zeta)}$} & \multicolumn{5}{|c|}{ Estimates } \\
\hline & 39.6554 & 27.354 & 2.92944 & 52.996 & \\
\hline & 2.15514 & $(2.0061)$ & (1.9812) & (1.376) & \\
\hline \multirow[t]{2}{*}{$\operatorname{McLx}(v, \beta, c, a, \zeta)$} & 2.1875 & 119.1751 & 12.4171 & 19.9243 & 75.6606 \\
\hline & $(0.5211)$ & (140.297) & $(20.845)$ & $(38.9601)$ & $(147.24)$ \\
\hline \multirow[t]{2}{*}{$\operatorname{TTLLx}(\mathrm{v}, \beta, \mathrm{a}, \zeta)$} & -0.80750 & 2.476633 & (15608.2) & $(38628.3)$ & \\
\hline & (0.13960) & $(0.54176)$ & (1602.37) & (123.936) & \\
\hline \multirow[t]{2}{*}{$\operatorname{KumLx}(v, \beta, a, \zeta)$} & 2.615021 & 100.2756 & 5.27710 & 78.6774 & \\
\hline & $(0.3822)$ & (120.486) & $(9.8116)$ & (186.006) & \\
\hline \multirow[t]{2}{*}{$\operatorname{BLx}(v, \beta, a, \zeta)$} & 3.60360 & 33.63870 & 4.830700 & 118.8374 & \\
\hline & $(0.6187)$ & $(63.7145)$ & (9.23820) & $(428.927)$ & \\
\hline \multirow[t]{2}{*}{$\operatorname{PRHRLx}(\beta, a, \zeta)$} & $3.73 \times 10^{6}$ & $4.707 \times 10^{-1}$ & $4.49 \times 10^{6}$ & & \\
\hline & $1.01 \times 10^{6}$ & $(0.00001)$ & 37.14684 & & \\
\hline \multirow[t]{2}{*}{$\operatorname{RTTLLx}(v, \beta, a)$} & -0.84732 & 5.52057 & 1.15678 & & \\
\hline & $(0.10010)$ & (1.18479) & (0.09588) & & \\
\hline \multirow[t]{2}{*}{$\operatorname{SGMLx}(\mathrm{v}, \mathrm{a}, \zeta)$} & $-1.04 \times 10^{-1}$ & $9.83 \times 10^{6}$ & $1.18 \times 10^{7}$ & & \\
\hline & $(0.1223)$ & $(4843.3)$ & $(501.04)$ & & \\
\hline \multirow[t]{2}{*}{$\operatorname{RMOLLx}(v, \beta, a)$} & 3.00116 & 0.66753 & 0.77531 & & \\
\hline & $(0.27521)$ & $(0.00876)$ & $(0.11651)$ & & \\
\hline \multirow[t]{2}{*}{$\operatorname{OLLLx}(\mathrm{v}, \mathrm{a}, \zeta)$} & 2.32636 & $\left(7.171 \times 10^{5}\right)$ & $\left.2.34 \times 10^{6}\right)$ & & \\
\hline & $\left(2.139 \times 10^{-1}\right)$ & $\left(1.192 \times 10^{4}\right)$ & $\left(2.61 \times 10^{1}\right)$ & & \\
\hline \multirow[t]{2}{*}{$\operatorname{GamLx}(\mathrm{v}, \mathrm{a}, \zeta)$} & 3.58760 & 52001.49 & 37029.66 & & \\
\hline & $(0.5133)$ & (7955.00) & (81.1644) & & \\
\hline \multirow[t]{2}{*}{$\operatorname{expLx}(\mathrm{v}, \mathrm{a}, \zeta)$} & 3.62610 & 20074.51 & 26257.68 & & \\
\hline & $(0.6236)$ & (2041.83) & (99.7417) & & \\
\hline \multirow[t]{2}{*}{$\operatorname{ROLLLx}(v, a)$} & 3.890564 & 0.57316 & & & \\
\hline & $(0.36524)$ & $(0.01946)$ & & & \\
\hline \multirow[t]{2}{*}{ RBHLx $(\mathrm{a}, \zeta)$} & 10801754 & 51367189 & & & \\
\hline & (983309.2) & (232312) & & & \\
\hline \multirow[t]{2}{*}{$\operatorname{Lx}(\mathrm{a}, \zeta)$} & 51425.35 & 131789.8 & & & \\
\hline & $(5933.49)$ & (296.119) & & & \\
\hline
\end{tabular}

Table 4: GOF statistics for data set I.

\begin{tabular}{cccccccc}
\hline Model & $-\ell$ & AIC & CAIC & BIC & HQIC & $A^{*}$ & $W^{*}$ \\
\hline MOLLx & $\mathbf{1 2 8 . 3 4 0 2}$ & $\mathbf{2 6 4 . 6 8 0 4}$ & $\mathbf{2 6 5 . 1 8 6 7}$ & $\mathbf{2 7 4 . 4 0 3 7}$ & $\mathbf{2 6 8 . 5 8 9 1}$ & $\mathbf{0 . 5 0 9 6}$ & $\mathbf{0 . 0 6 4 4}$ \\
McLx & 129.8023 & 269.6045 & 270.3640 & 281.8178 & 274.5170 & 0.6672 & 0.0858 \\
RMOLLx & 132.1993 & 270.3987 & 270.6987 & 277.6911 & 273.3302 & 0.7593 & 0.0772 \\
OLLLx & 134.4235 & 274.8470 & 275.1470 & 282.1394 & 277.7785 & 0.9407 & 0.1009 \\
TTLLx & 135.5700 & 279.1400 & 279.6464 & 288.8633 & 283.0487 & 1.1257 & 0.1270 \\
GamLx & 138.4042 & 282.8083 & 283.1046 & 290.1363 & 285.7559 & 1.3666 & 0.1618 \\
BLx & 138.7177 & 285.4354 & 285.9354 & 295.2059 & 289.3654 & 1.4084 & 0.1680 \\
expLx & 141.3997 & 288.7994 & 289.0957 & 296.1273 & 291.7469 & 1.7435 & 0.2194 \\
ROLLLx & 142.8452 & 289.6904 & 289.8385 & 294.5520 & 291.6447 & 1.9566 & 0.2554 \\
SGMLx & 143.0874 & 292.1747 & 292.4747 & 299.4672 & 295.1062 & 1.3467 & 0.1578 \\
RTTLLx & 153.9809 & 313.9618 & 314.2618 & 321.2542 & 316.8933 & 3.7527 & 0.5592 \\
PRHRLx & 162.8770 & 331.7540 & 332.0540 & 339.0464 & 334.6855 & 1.3672 & 0.1609 \\
Lx & 164.9884 & 333.9767 & 334.1230 & 338.8619 & 335.9417 & 1.3976 & 0.1665 \\
RBHLx & 168.6040 & 341.2081 & 341.3562 & 346.0697 & 343.1624 & 1.6711 & 0.2069 \\
\hline
\end{tabular}


Table 5: MLEs and SEs for data set II.

\begin{tabular}{|c|c|c|c|c|}
\hline Model & & Estimates & & \\
\hline \multirow[t]{2}{*}{$\operatorname{MOLLx}(\mathrm{v}, \beta, \mathrm{a}, \zeta)$} & 10.6132 & 2.6823 & 12.6454 & 26.2893 \\
\hline & (6.1392) & (4.4842) & (21.142) & $(53.722)$ \\
\hline \multirow[t]{2}{*}{$\operatorname{KumLx}(v, \beta, a, \zeta)$} & 1.66912 & 60.5673 & 2.56490 & 65.06400 \\
\hline & $(0.2570)$ & $(86.0131)$ & $(4.7589)$ & $(177.592)$ \\
\hline \multirow[t]{2}{*}{$\operatorname{BLx}(v, \beta, a, \zeta)$} & 1.921821 & 31.2594 & 4.96843 & 169.5719 \\
\hline & $(0.3184)$ & $(316.841)$ & $(50.5283)$ & (339.207) \\
\hline \multirow[t]{2}{*}{$\operatorname{TTLLx}(\mathrm{v}, \beta, \mathrm{a}, \zeta)$} & $(-0.6070)$ & 1.785780 & 2123.391 & 4822.789 \\
\hline & $(0.21371)$ & $(0.41522)$ & $(163.915)$ & (200.009) \\
\hline \multirow[t]{2}{*}{$\operatorname{PRHRLx}(\beta, \mathrm{a}, \zeta)$} & $1.591 \times 10^{6}$ & $3.934 \times 10^{-1}$ & $1.302 \times 10^{6}$ & \\
\hline & $2.013 \times 10^{3}$ & $0.0004 \times 10^{-1}$ & $0.95 \times 10^{6}$ & \\
\hline \multirow[t]{2}{*}{$\operatorname{RTTLLx}(v, \beta, a)$} & -0.67145 & 2.74496 & 1.012377 & \\
\hline & $(0.18746)$ & $(0.6696)$ & $(0.11405)$ & \\
\hline \multirow[t]{2}{*}{$\operatorname{SGMLx}(\mathrm{v}, \mathrm{a}, \zeta)$} & $-1.04 \times 10^{-1}$ & $6.45 \times 10^{6}$ & $6.33 \times 10^{6}$ & \\
\hline & $\left(4.1 \times 10^{-1^{0}}\right)$ & $\left(3.21 \times 10^{6}\right)$ & $(3.85731)$ & \\
\hline \multirow[t]{2}{*}{$\operatorname{RMOLLx}(v, \beta, a)$} & 1.927075 & 1.349825 & 0.43660 & \\
\hline & $(0.21096)$ & $(12.6473)$ & (4.09087) & \\
\hline \multirow[t]{2}{*}{$\operatorname{OLLLx}(\mathrm{v}, \mathrm{a}, \zeta)$} & 1.664199 & $6.340 \times 10^{5}$ & $2.01 \times 10^{6}$ & \\
\hline & $\left(1.79 \times 10^{-1}\right)$ & $\left(1.68 \times 10^{4}\right)$ & $7.22 \times 10^{6}$ & \\
\hline \multirow[t]{2}{*}{$\operatorname{GamLx}(\mathrm{v}, \mathrm{a}, \zeta)$} & 1.907312 & 35842.433 & 39197.57 & \\
\hline & $(0.32133)$ & $(6945.07)$ & (151.653) & \\
\hline \multirow[t]{2}{*}{$\operatorname{expLx}(\mathrm{v}, \mathrm{a}, \zeta)$} & 1.91454 & 22971.154 & 32881.99 & \\
\hline & $(0.3482)$ & (3209.533) & $(162.230)$ & \\
\hline \multirow[t]{2}{*}{$\operatorname{ROLLLx}(v, a)$} & 2.37233 & 0.691094 & & \\
\hline & $(0.26825)$ & $(0.04488)$ & & \\
\hline \multirow[t]{2}{*}{ RBHLx $(a, \zeta)$} & 14055522 & 53203423 & & \\
\hline & (422.005) & $(28.52323)$ & & \\
\hline \multirow[t]{2}{*}{$\operatorname{Lx}(a, \zeta)$} & 99269.78 & 207019.37 & & \\
\hline & (11863.5) & $(301.2366)$ & & \\
\hline
\end{tabular}

Table 6: GOF statistics for data set II.

\begin{tabular}{cccccccc}
\hline Model & $-\ell$ & AIC & CAIC & BIC & HQIC & $A^{*}$ & $W^{*}$ \\
\hline MOLLx & $\mathbf{9 8 . 9 1 8 1 7}$ & $\mathbf{2 0 5 . 8 3 6 3}$ & $\mathbf{2 0 6 . 5 2 6 0}$ & $\mathbf{2 1 4 . 4 0 8 9}$ & $\mathbf{2 0 9 . 2 0 8}$ & $\mathbf{0 . 2 9 3 9}$ & $\mathbf{0 . 0 4 6 9}$ \\
KumLx & 100.8676 & 209.7353 & 210.4249 & 218.3078 & 213.1069 & 0.7391 & 0.1219 \\
RMOLLx & 101.8349 & 209.6698 & 210.0766 & 216.0992 & 212.1985 & 0.8836 & 0.1459 \\
TTLLx & 102.4498 & 212.8996 & 213.5893 & 221.4722 & 216.2713 & 0.9431 & 0.1554 \\
GamLx & 102.8332 & 211.6663 & 212.0730 & 218.0958 & 214.1951 & 1.1120 & 0.1836 \\
SGMLx & 102.8940 & 211.7881 & 212.1949 & 218.2175 & 214.3168 & 1.1134 & 0.1839 \\
BLx & 102.9611 & 213.9223 & 214.6119 & 222.4948 & 217.2939 & 1.1336 & 0.1872 \\
expLx & 103.5498 & 213.0995 & 213.5063 & 219.5289 & 215.6282 & 1.2331 & 0.2037 \\
OLLLx & 104.9041 & 215.8082 & 216.2150 & 222.2376 & 218.3369 & 0.9424 & 0.1545 \\
PRHRLx & 109.2986 & 224.5973 & 225.004 & 231.0267 & 227.1261 & 1.1264 & 0.1861 \\
Lx & 109.2988 & 222.5976 & 222.7976 & 226.8839 & 224.2834 & 1.1265 & 0.1861 \\
ROLLLx & 110.7287 & 225.4573 & 225.6573 & 229.7436 & 227.1431 & 2.3472 & 0.3908 \\
RTTLLx & 112.1855 & 230.3710 & 230.7778 & 236.8004 & 232.8997 & 2.6875 & 0.4532 \\
RBHLx & 112.6005 & 229.2011 & 229.4011 & 233.4873 & 230.8869 & 1.3984 & 0.2316 \\
\hline
\end{tabular}



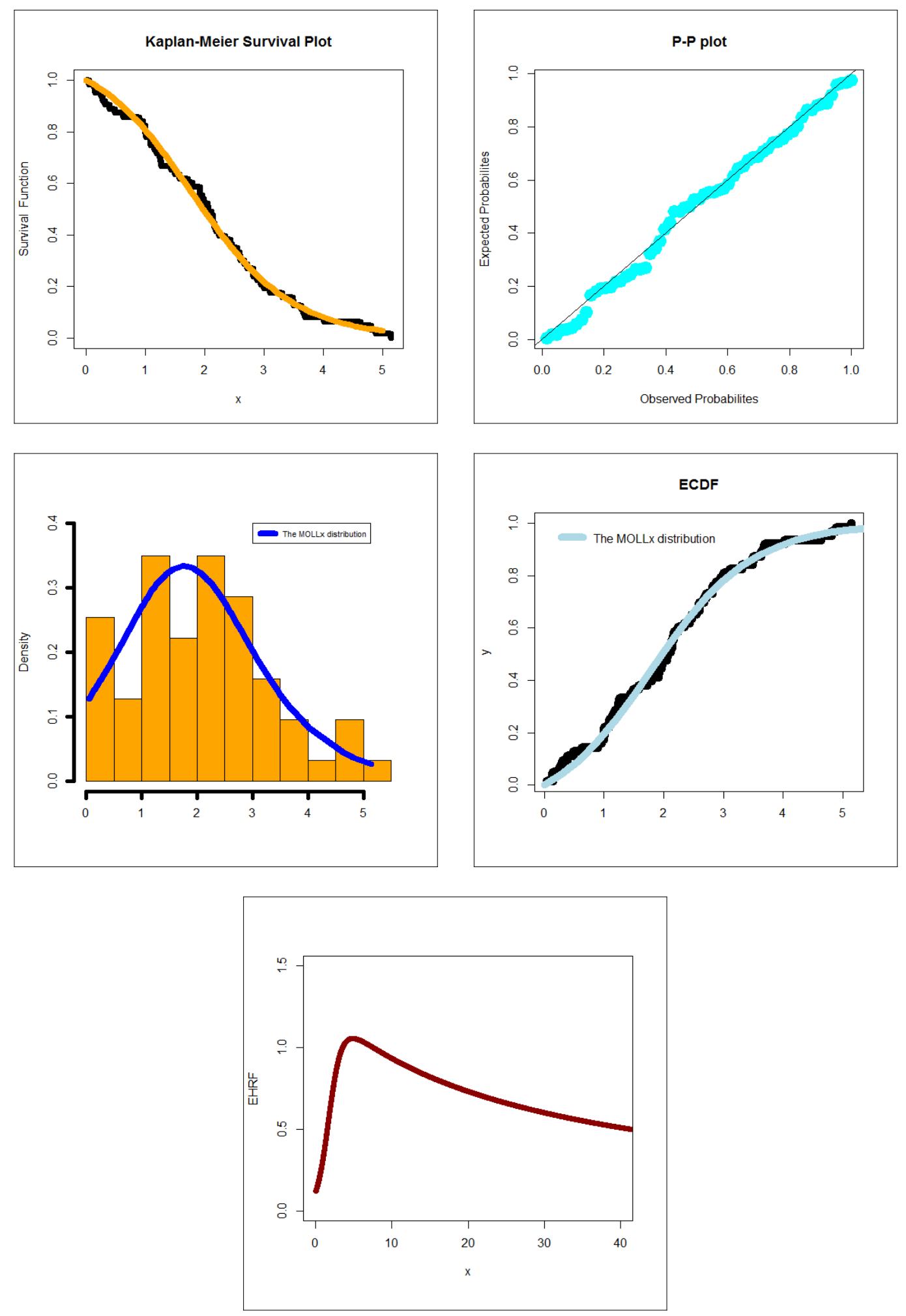

Figure 11: EKMS plot, P-P plot, EPDF, ECDF and EHRF for data set II. 

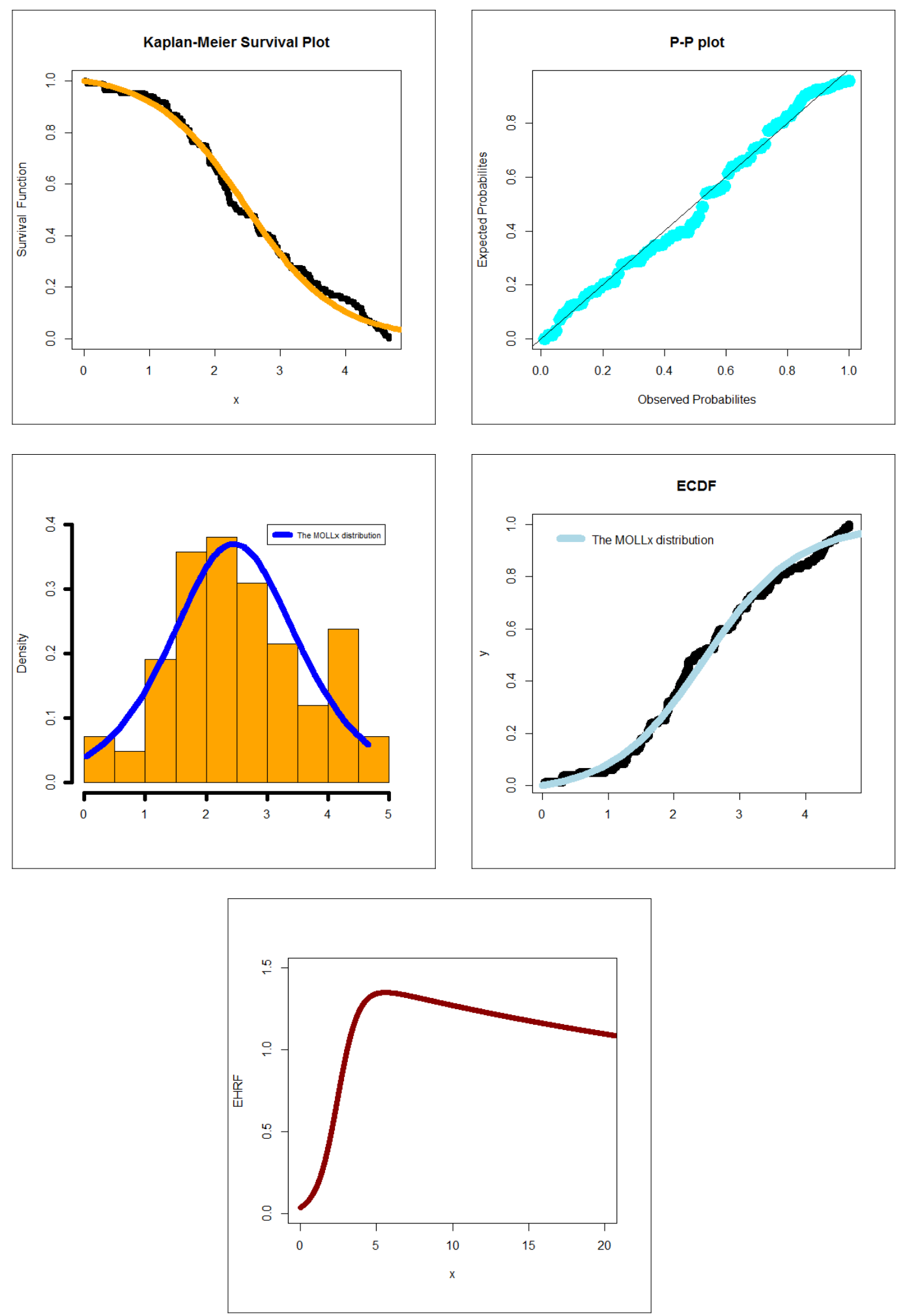

Figure 10: EKMS plot, P-P plot, EPDF, ECDF and EHRF for data set I. 


\section{Conclusions}

A new four parameter lifetime model called the Marshall-Olkin Lehmann Lomax (MOLLx) is proposed and studied. The MOLLx density function can be "monotonically right skewed", "symmetric", "monotonically left skewed" and "uniformed density". The MOLLx failure rate function can be "monotonically decreasing", " monotonically increasing" and "constant". The new MOLLx density can be expressed as a mixture of the exponentiated Lomax model. The skewness of the MOLLx distribution can negative and positive. The spread for the kurtosis of the MOLLX model is ranging from -1129.85 to 311.698 . The index of dispersion for the MOLLx model can be in $(0,1)$ and also $>1$ so it may be used as an "under-dispersed" and "over-dispersed" model. We derived some new bivariate versions of the MOLLx distribution via Farlie Gumbel Morgenstern family, modified Farlie Gumbel Morgenstern family, Clayton Copula and Renyi's entropy. The maximum likelihood method is used to estimate the MOLLx parameters. Using the "biases" and "mean squared errors", we performed simulation experiments for assessing the finite sample behavior of the maximum likelihood estimators. It is noted that, the biases for all parameters are generally negative and tends to 0 as $n \rightarrow \infty$ and the mean squared errors for all parameter decrease to 0 as $n \rightarrow \infty$. The MOLLx model deserved to be chosen as the best model among many well-known Lomax extension such as exponentiated Lomax, gamma Lomax, Kumaraswamy Lomax, odd log-logistic Lomax, Macdonald Lomax, beta Lomax, reduced odd log-logistic Lomax, reduced Burr-Hatke Lomax, reduced MOLLx, special generalized mixture Lomax and the standard Lomax distributions in modeling the "failure times" and the "service times" data sets.

As a future separate works, we can consider and apply many new useful goodness-of-fit statistic tests for the right censored distributional validation such as the Nikulin-Rao-Robson goodness-of-fit statistic test, modified NikulinRao-Robson goodness-of-fit statistic test, Bagdonavicius-Nikulin goodness-of-fit statistic test and modified Bagdonavicius-Nikulin goodness-of-fit statistic test as recently performed by Ibrahim et al. (2019), Goual et al. (2019, 2020), Mansour et al. (2020a,d), Yadav et al. (2020) and Goual and Yousof (2020), among others.

\section{References}

1. Aarset, M. V. (1987). How to identify a bathtub hazard rate. IEEE Transactions on Reliability, 36(1), 106-108.

2. Aboraya, M. (2019). A New Extension of the Lomax Distribution with Properties and Applications to Failure Times Data. Pakistan Journal of Statistics and Operation Research (15)2, 461-479.

3. Aboraya, M. and Butt, N. S. (2019). Extended Weibull Burr XII Distribution: Properties and Applications. Pakistan Journal of Statistics and Operation Research, (15)4, 891-903.

4. Al-babtain, A. A., Elbatal, I. and Yousof, H. M. (2020). A new flexible three-parameter model: properties, Clayton copula, and modeling real data. Symmetry, 12(3), 440.

5. Ali, M. M., Yousof, H. M. and Ibrahim, M. (2021a). A new version of the generalized Rayleigh distribution with copula, properties, applications and different methods of estimation. Optimal Decision Making in Operations Research \& Statistics: Methodologies and Applications, VOL 1, to appear.

6. Ali, M. M., Ibrahim, M. and Yousof, H. M. (2021b). Expanding the Burr X model: properties, copula, real data modeling and different methods of estimation. Optimal Decision Making in Operations Research \& Statistics: Methodologies and Applications, VOL 1, to appear.

7. Altun, E., Yousof, H. M. and Hamedani, G. G. (2018a). A new log-location regression model with influence diagnostics and residual analysis. Facta Universitatis, Series: Mathematics and Informatics, 33(3), 417-449.

8. Altun, E., Yousof, H. M., Chakraborty, S. and Handique, L. (2018b). Zografos-Balakrishnan Burr XII distribution: regression modeling and applications. International Journal of Mathematics and Statistics, 19(3), 46-70.

9. Aryal, G. R., Ortega, E. M., Hamedani, G. G. and Yousof, H. M. (2017). The Topp Leone Generated Weibull distribution: regression model, characterizations and applications, International Journal of Statistics and Probability, 6, 126-141.

10. Atkinson, A.B. and Harrison, A.J. (1978). Distribution of Personal Wealth in Britain (Cambridge University Press, Cambridge).

11. Balkema, A.A. and de Hann, L. Residual life at great age, Annals of Probability 2, 972-804, 1974.

12. Bryson, M. C. (1974). Heavy-tailed distribution: properties and tests, Technometrics 16, 161-68.

13. Chahkandi, M. and Ganjali, M. (2009). On some lifetime distributions with decreasing failure rate, Computational Statistics and Data Analysis 53, 4433-4440.

14. Chao, M. T. (1970). The asymptotic behavior of Bayes' estimators. The Annals of Mathematical Statistics, 41(2), 601-608.

15. Chesneau, C. and Yousof, H. M. (2021). On a special generalized mixture class of probabilistic models. Journal 
of Nonlinear Modeling and Analysis, 3(1), 71-92.

16. Cordeiro, G. M., Yousof, H. M., Ramires, T. G. and Ortega, E. M. M. (2018). The Burr XII system of densities: properties, regression model and applications. Journal of Statistical Computation and Simulation, 88(3), 432456.

17. Durbey, S. D. (1970). Compound gamma, beta and F distributions, Metrika 16, 27-31.

18. Gupta, R. C., Gupta, P. L. and Gupta, R. D. (1998). Modeling failure time data by Lehman alternatives. Communications in Statistics-Theory and methods, 27(4), 887-904.

19. Corbellini, A., Crosato, L., Ganugi, P and Mazzoli, M. (2007). Fitting Pareto II distributions on firm size: Statistical methodology and economic puzzles. Paper presented at the International Conference on Applied Stochastic Models and Data Analysis, Chania, Crete.

20. Cordeiro, G. M., Ortega, E. M. and Popovic, B. V. (2015). The gamma-Lomax distribution. Journal of Statistical computation and Simulation, 85(2), 305-319.

21. Elbiely, M. M. and Yousof, H. M. (2018). A New Extension of the Lomax Distribution and its Applications, Journal of Statistics and Applications, 2(1), 18-34.

22. Elgohari, H. and Yousof, H. M. (2020a). A Generalization of Lomax Distribution with Properties, Copula and Real Data Applications. Pakistan Journal of Statistics and Operation Research, 16(4), 697-711.

23. Elgohari, H. and Yousof, H. M. (2020b). New Extension of Weibull Distribution: Copula, Mathematical Properties and Data Modeling. Statistics, Optimization \& Information Computing, 8(4), 972-993.

24. Elgohari, H., Ibrahim, M. and Yousof, H. M. (2021). A New Probability Distribution for Modeling Failure and Service Times: Properties, Copulas and Various Estimation Methods. Statistics, Optimization \& Information Computing, forthcoming.

25. Farlie, D. J. G. (1960) The performance of some correlation coefficients for a general bivariate distribution. Biometrika, 47, 307-323.

26. Gumbel, E. J. (1961). Bivariate logistic distributions. Journal of the American Statistical Association, 56(294), 335-349.

27. Gumbel, E. J. (1960) Bivariate exponential distributions. Journ. Amer. Statist. Assoc., 55, 698-707.

28. Harris, C.M. (1968). The Pareto distribution as a queue service descipline, Operations Research, 16, $307-313$.

29. Hassan, A.S. and Al-Ghamdi, A.S. (2009). Optimum step stress accelerated life testing for Lomax distribution, Journal of Applied Sciences Research, 5, 2153-2164.

30. Ibragimov, I. A. (1962). Some limit theorems for stationary processes. Theory of Probability \& Its Applications, 7(4), 349-382.

31. Ibrahim, M. and Yousof, H. M. (2020). A new generalized Lomax model: statistical properties and applications, Journal of Data Science, 18(1), 190 - 217.

32. Ibrahim, M. (2019). A new extended Fréchet distribution: properties and estimation. Pak. J. Stat. Oper. Res.,15 (3), 773-796.

33. Ibrahim, M. (2020a). The compound Poisson Rayleigh Burr XII distribution: properties and applications. Journal of Applied Probability and Statistics, 15(1), 73-97.

34. Ibrahim, M. (2020b). The generalized odd Log-logistic Nadarajah Haghighi distribution: statistical properties and different methods of estimation. J. Appl. Probab. Stat, 15, 61-84.

35. Ibrahim, M., Yadav, A. S., Yousof, H. M., Goual, H. and Hamedani, G. G. (2019). A new extension of Lindley distribution: modified validation test, characterizations and different methods of estimation. Communications for Statistical Applications and Methods, 26(5), 473-495.

36. Johnson, N. L. and Kotz, S. (1975) On some generalized Farlie-Gumbel-Morgenstern distributions. Commun. Stat. Theory, 4, 415-427.

37. Johnson, N. L. and Kotz, S. (1977) On some generalized Farlie-Gumbel-Morgenstern distributions- II: Regression, correlation and further generalizations. Commun. Stat.Theory, 6, 485-496.

38. Lemonte, A. J. and Cordeiro, G. M. (2013). An extended Lomax distribution. Statistics, 47(4), 800-816.

39. Lomax, K.S. (1954). Business failures: Another example of the analysis of failure data, Journal of the American Statistical Association, 49, 847-852.

40. Gad, A. M., Hamedani, G. G., Salehabadi, S. M. and Yousof, H. M. (2019). The Burr XII-Burr XII distribution: mathematical properties and characterizations. Pakistan Journal of Statistics, 35(3), 229-248.

41. Gleaton, J. U. and Lynch, J.D. (2006). Properties of generalized loglogistic families of lifetime distributions. Journal of Probability and Statistical Science, 4, 51-64.

42. Goual, H. and Yousof, H. M. (2020). Validation of Burr XII inverse Rayleigh model via a modified chi-squared goodness-of-fit test. Journal of Applied Statistics, 47(3), 393-423.

43. Goual, H., Yousof, H. M. and Ali, M. M. (2019). Validation of the odd Lindley exponentiated exponential by a 
modified goodness of fit test with applications to censored and complete data. Pakistan Journal of Statistics an Operation Research, 15(3), 745-771.

44. Goual, H., Yousof, H. M. and Ali, M. M. (2020). Lomax inverse Weibull model: properties, applications and a modified Chi-squared goodness-of-fit test for validation, Journal of Nonlinear Science and Applications. 13(6), 330-353.

45. Gumbel, E. J. (1961). Bivariate logistic distributions. Journal of the American Statistical Association, 56(294), 335-349.

46. Gumbel, E. J. (1960) Bivariate exponential distributions. Journ. Amer. Statist. Assoc., 55, 698-707.

47. Mansour, M. M., Ibrahim, M., Aidi, K., Shafique Butt, N., Ali, M. M., Yousof, H. M. and Hamed, M. S. (2020a). A New Log-Logistic Lifetime Model with Mathematical Properties, Copula, Modified Goodness-of-Fit Test for Validation and Real Data Modeling. Mathematics, 8(9), 1508.

48. Mansour, M. M., Butt, N. S., Ansari, S. I., Yousof, H. M., Ali, M. M. and Ibrahim, M. (2020b). A new exponentiated Weibull distribution's extension: copula, mathematical properties and applications. Contributions to Mathematics, 1 (2020) 57-66. DOI: 10.47443/cm.2020.0018

49. Mansour, M., Korkmaz, M. Ç., Ali, M. M., Yousof, H. M., Ansari, S. I. and Ibrahim, M. (2020c). A generalization of the exponentiated Weibull model with properties, Copula and application. Eurasian Bulletin of Mathematics, 3(2), 84-102.

50. Mansour, M., Rasekhi, M., Ibrahim, M., Aidi, K., Yousof, H. M. and Elrazik, E. A. (2020d). A New Parametric Life Distribution with Modified Bagdonavičius-Nikulin Goodness-of-Fit Test for Censored Validation, Properties, Applications, and Different Estimation Methods. Entropy, 22(5), 592.

51. Mansour, M., Yousof, H. M., Shehata, W. A. and Ibrahim, M. (2020e). A new two parameter Burr XII distribution: properties, copula, different estimation methods and modeling acute bone cancer data. Journal of Nonlinear Science and Applications, 13(5), 223-238.

52. Mansour, M. M., Butt, N. S., Yousof, H. M., Ansari, S. I. and Ibrahim, M. (2020f). A Generalization of Reciprocal Exponential Model: Clayton Copula, Statistical Properties and Modeling Skewed and Symmetric Real Data Sets. Pakistan Journal of Statistics and Operation Research, 16(2), 373-386.

53. Morgenstern, D. (1956). Einfache beispiele zweidimensionaler verteilungen. Mitteilingsblatt fur Mathematische Statistik, 8, 234-235.

54. Murthy, D.N.P. Xie, M. and Jiang, R. (2004). Weibull Models, Wiley.

55. Nasir, M. A., Korkmaz, M. C., Jamal, F. and Yousof, H. M. (2018). On a new Weibull Burr XII distribution for lifetime data. Sohag Journal of Mathematics, 5(2), 47-56.

56. Pougaza, D. B. and Djafari, M. A. (2011). Maximum entropies copulas. Proceedings of the 30th international workshop on Bayesian inference and maximum Entropy methods in Science and Engineering, 329-336.

57. Rodriguez-Lallena, J. A. and Ubeda-Flores, M. (2004). A new class of bivariate copulas. Statistics and Probability Letters, 66, 315-25.

58. Tadikamalla, P. R. (1980). A look at the Burr and realted distributions, International Statistical Review 48, 337 344.

59. Yadav, A.S., Goual, H., Alotaibi, R.M. Rezk, H., Ali, M.M. and Yousof, H. M. (2020). Validation of the ToppLeone-Lomax model via a modified Nikulin-Rao-Robson goodness-of-fit test with different methods of estimation. Symmetry, 12, 1-26. doi: 10.3390/sym12010057

60. Tahir, M. H., Cordeiro, G. M., Mansoor, M., \& Zubeir, M. (2015). The Weibull-Lomax distribution: properties and applications. Hacettepe Journal of Mathematics and Statistics, 44(2), 461-480.

61. Yousof, H. M., Ahsanullah, M. and Khalil, M. G. (2019). A New Zero-Truncated Version of the Poisson Burr XII Distribution: Characterizations and Properties. Journal of Statistical Theory and Applications, 18(1), 1-11.

62. Yousof, H. M., Alizadeh, M., Jahanshahiand, S. M. A., Ramires, T. G., Ghosh, I. and Hamedani, G. G. (2017). The transmuted Topp-Leone $\mathrm{G}$ family of distributions: theory, characterizations and applications. Journal of Data Science, 15(4), 723-740.

63. Yousof, H. M., Altun, E., Ramires, T. G., Alizadeh, M. and Rasekhi, M. (2018). A new family of distributions with properties, regression models and applications, Journal of Statistics and Management Systems, 21, 1, 163188.

64. Yousof, H. M., Majumder, M., Jahanshahi, S. M. A., Ali, M. M. and Hamedani G. G. (2018). A new Weibull class of distributions: theory, characterizations and applications, Journal of Statistical Research of Iran, 15, 4583. 